\title{
RELIGIOUS MODERATION IN ISLAMIC EDUCATION LEARNING TO COUNTER RADICALISM: Study at SMAN 1 Sugihwaras Bojonegoro
}

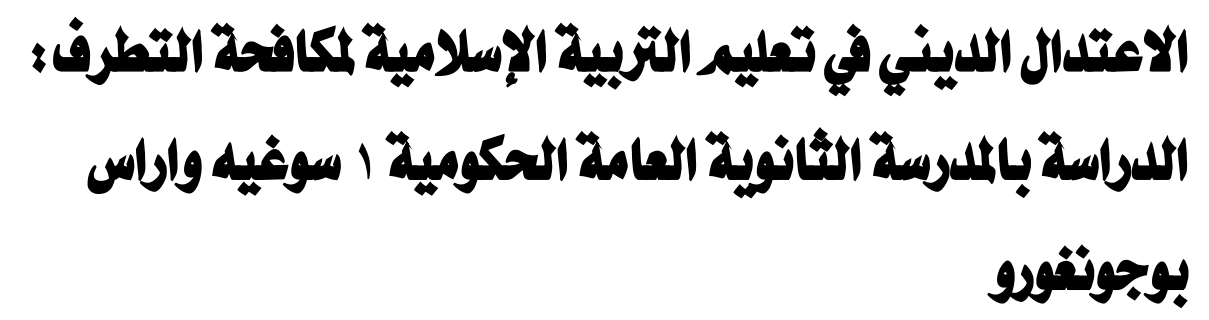

Zeid B. Smeer and Inayatur Rosyidah

Universitas Islam Negeri Maulana Malik Ibrahim Malang, Indonesia E-mail: inayaturrosyidah11@gmail.com

\section{Abstract}

Among the negative impacts of advances in digital technology is the spread of false information based on religion which plays a role in shaping young people to become radicalized and justifying violence for religious solidarity. Efforts should be made to internalize the values of religious moderation in Islamic Education learning (PAI) in schools, so that students are able to understand, live and practice moderate Islamic values according to the Islamic vision, namely Islam Rahmat li al-Âlamîn. This research is a descriptive qualitative research with the object of research at SMAN 1 Sugihwaras Bojonegoro. Data obtained through interviews, documentation, and observation. The data analysis technique used Miles and Huberman's model in the form of data reduction, data display, and conclusion drawing. The data validity used triangulation technique. The findings show that the internalization of 
religious moderation in Islamic education learning to counter radicalism can be started by determining educational policies and objectives, as well as through the design of a the prescribed/intended curriculum and a hidden curriculum. Meanwhile, the contribution of religious moderation in general is to mature students' intellectual, mental and social skills as multicultural social beings with respect for diversity and a willingness to cooperate fairly with anyone.

من الآثار السلبية لتقدم التكنولوجيا الرقمية انتشار المعلومات الكاذبة

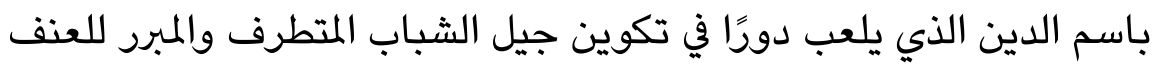
من أجل التضامن الديني. وينبغي غرس قيم الاعتدال الديني في تعليم

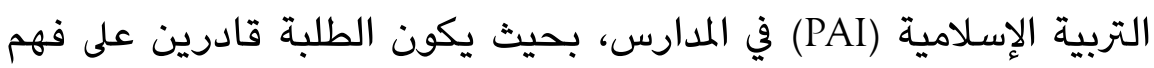
وتقدير وممارسة القيم الإسلامية المعتدلة وفقًا لرؤية الإسلام، وهي الإسلة الإسلام

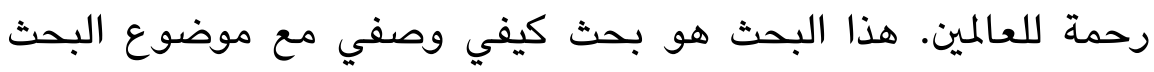

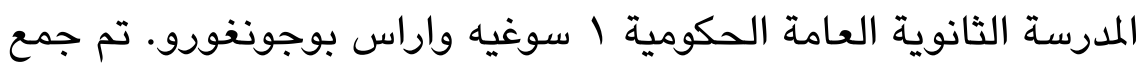
البيانات من خلال المقابلة والوثائق والملاحظة. تستخدم طريقة تحليل

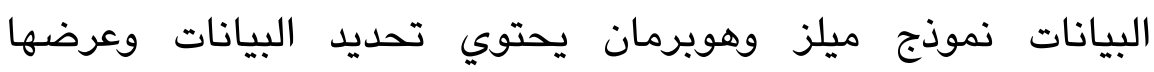
والاستنتاج منها. وطريقة التثليث للتحقق من صحة البيانات. أظهرت ودئرت

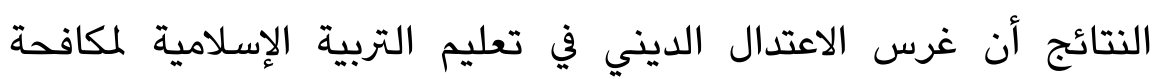
التطرف يتم من خلال وضع السياسات والأهداف التربوية، والمنهج الدراسي المكتوب (المنهج المقرر/المقصود) والمنهج الدراسي المكتوم (المنهج الخفي).

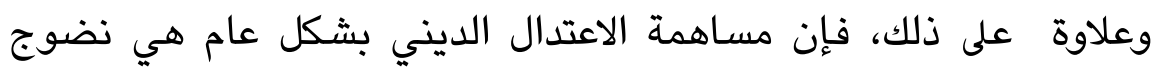

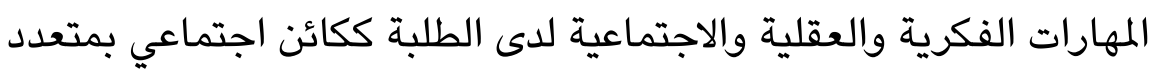
الثقافات مع احترام التعددية والرغبة في التعاون مع أي شخص ولية لاحس بالعدل.

Keywords: internalization; Islamic education; religious moderation

Received: March 23, 2021; Accepted: July 14, 2021 


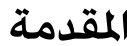

إن أصعب التحديات التي تواجهها إندونيسيا في بناء الاتساق والانسجام في

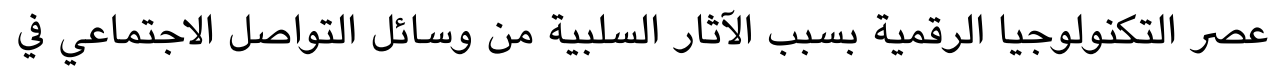
صورة نشر المعلومات الكاذبة باسم الدين يلعب دورا في تكوين جيل الشباب

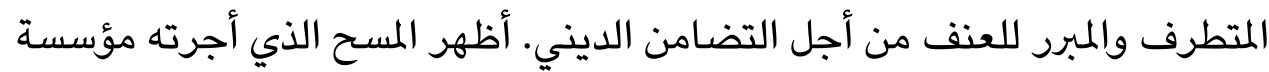

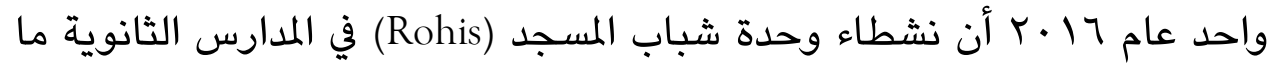

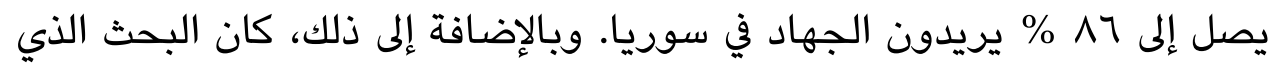
أجراه مركز البحوث لدراسة الإسلام والمجتمع في جامعة شريف هدائ هداية الله

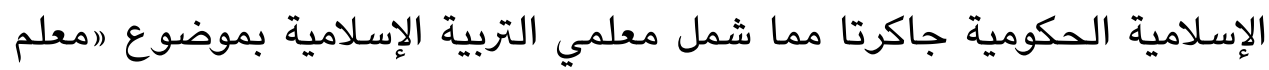

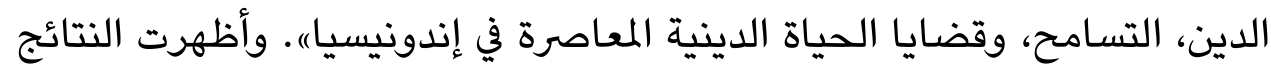

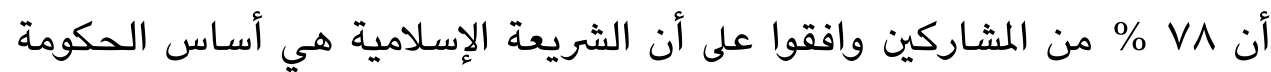
الإندونيسية، وصرح VV م من المشاركين بتأييدهم لنضال الشريعة الإسلامية التي قامت بها المنظمات الموجودة (2018 Sondang). بالإضافة إلى ذلك، استنادا إلى دراسة استقصائية أجرتها هيئة نقل إندونيسيا في عام \1 • ب حول آراء أو مواقف وأفعال أو سلوكيات تنوع المعلمين

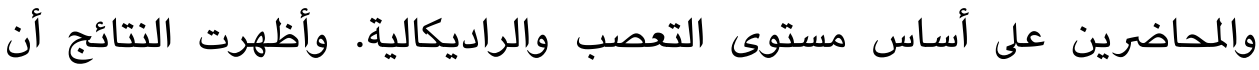

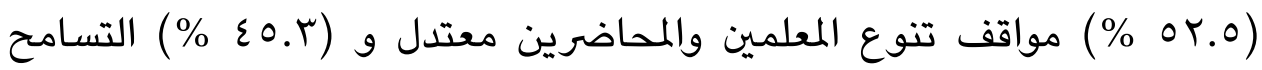

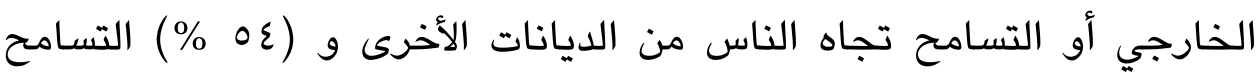

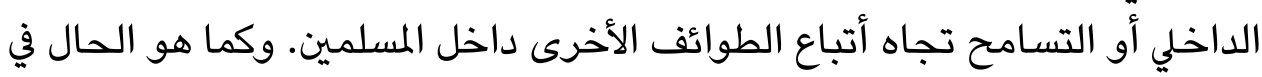

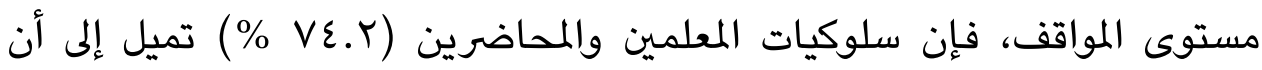

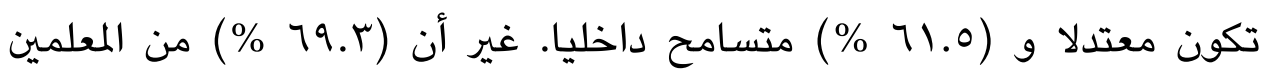

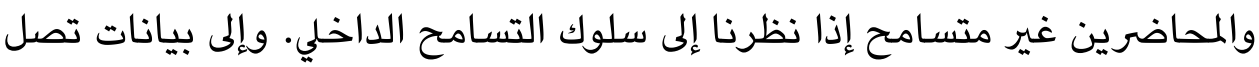
إلى AV.19 \% منهم وافقوا على الحظر الذي فرضته الحكومة على وجود جماعات الأقليات التي تعتبر منحرفة عن التعاليم الإسلامية (Faozan 2020) وينبغي معالجة هذه الحالة فوريا، نظرا إلى إندونيسيا كبلد بمتعدد الإسيه الثقافات مما يضم ثقافات وقبائل وديانات متنوعة، ولأنها ستعرقل تحقيق 
إندونيسيا السلام والمتسامح من خلال التمسك بشعار Bhinneka Tunggal Ika. ومن التعليم، يحتاج الطلبة إلى أن يكونوا مجهزين بالكفاءة الفكرية والأخلاقية في سياق إندونيسي و ديني مما ينسجم مع المعايير والقيم النبيلة والهوية الوطنية.

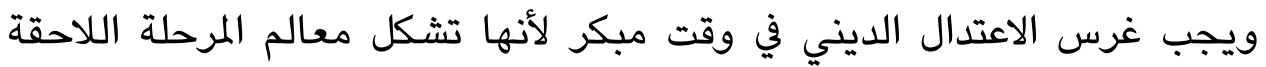
للتنمية. يمكن غرس قيم الاعتدال الإسلامي من خلال مادة التربية الإسلامية

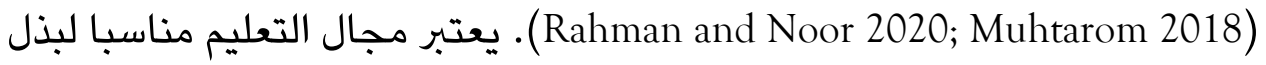
الجهود في الاستيعاب، وتحويل الوعي، والسلوك البشري. وسيلعب التعليم والتدريس اليانعي والمخطط له دورا نشطا في تطوير الإمكانات البناءة .(Nashuddin 2020)

ترتبط التربية الإسلامية ارتباطا وثيقا بتوفير الكفاءة الأخلاقية لتحقيق المساواة في الانسجام بين المتدينين. ويرى مهيمن علي أن التربية الإسلامية ليست اليستاهيه

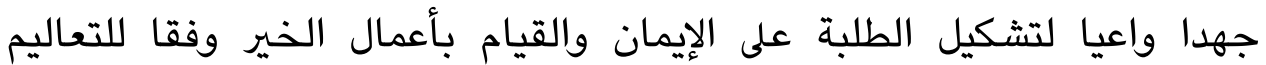
الإسلامية من خلال التوجيه والتدريس، ولكن أيضا تقديم مبادئ توجيهية لتكون

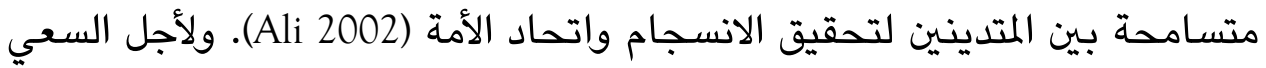
إلى تعليم التربية الإسلامية الوسطية وفقا لرؤية الإسلام “الإسلام رحمة للعالمين” وكونها الاستيعاب، حتى يفهم الطلبة القيم الإسلامية الوسطية ويمارسها ويطبقها في الحياة اليومية. يمكن فهم الاعتدال الديني بأبسط معانيه على أنه دعوة إلى الدعوة المتسامحة والمعارضة للأفكار المتطرفة (Afrizal and Lubis 2015).

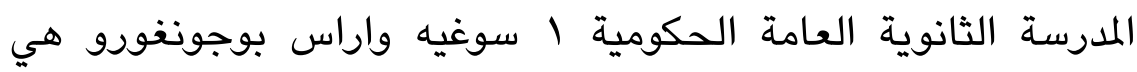

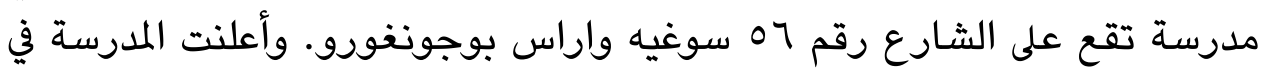

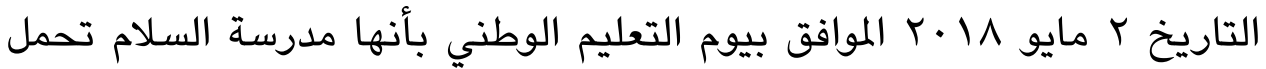
شعار “،مدرسة السلام، تدعم السلام، تحترم الاختلاف وتحافظ على صلة الأخوة بين الطلبة". وظهر السؤال وسط حالات طلبة هذه المدرسة غير متجانسة، كيف يتم غرس الاعتدال الديني ومساهمته في تعليم التربية الإسلامية في الملدرسة الثانوية العامة الحكومية ا سوغيه واراس بوجونغوري الديدي 
يمكن تطوير الاعتدال الديني من خلال مادة التربية الإسلامية كأداة رئيسية لبناء الشخصية الدينية. ويكون إدراج رسالة السلام والاحترام المتبادل والتسامح والحاجة إلى العيش في السلام في مضمون المادة التعليمية. بدءا من إلداج مرحلة الطفولة المبكرة إلى الجامعية. ويتم غرس الاعتدال الديني في المؤسسات

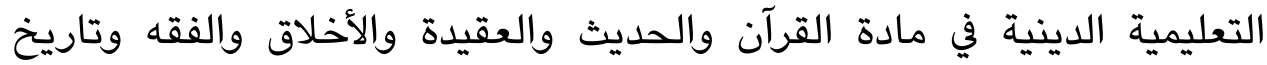

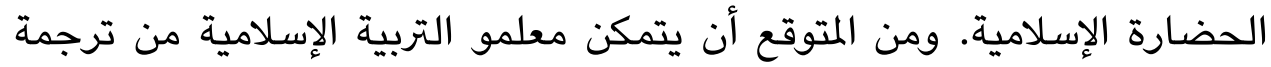
محتوى الاعتدال الديني إلى مواد تعليمية للتربية الإسلامية بشكل فئ فعال.

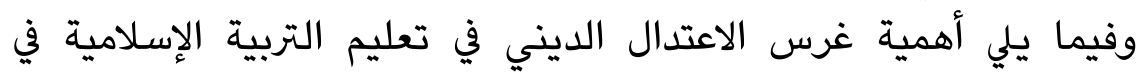

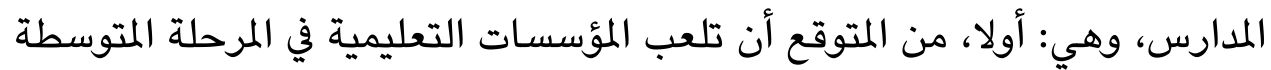

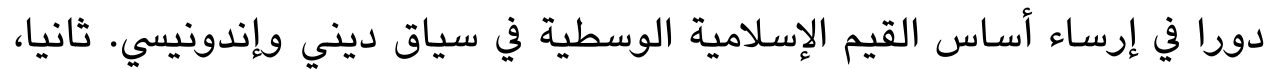
يجب أن يكون التعليم جاهزا لتشكيل جيل يدرك ويفهم تعددية المجتمع الإندونيسي غير المتجانس. ثالثا، يكون الاعتدال الديني في التعليم يصد الخطاب ضد الخطابات السلبية حول التعصب والتطرف باسم الدين أو العرق. رابعا، تعزيز الاعتدال، سواء في العقلية أو الكلام أو موقف الاعتدال لكونه مسؤولية

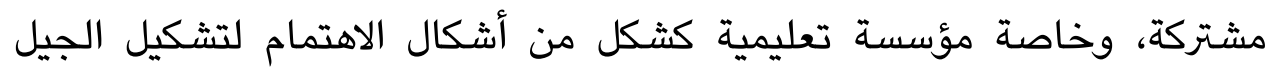
المستقبل من الأمة المستعدة للسيطرة على اتحاد ووحدة الأمة بروح الإنسانية والأخوة والتسامح. تهتم الدراسة في هذه الورقة بوضع غرس الامه الاعتدال الديني ومساهمته في تعليم التربية الإسلامية في المدرسة (دراسة الحالة في المدرسة الثاندانوية الثانية العامة الحكومية ا سوغيه واراس بوجونغورو).

\section{منهجية البحث}

ويالنظر إلى التفسيرات النظرية التي تريد أن تبنى (مستندة إلى البيانات)،

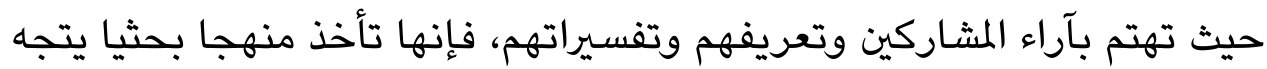
ويهدف إلى فهم مشكلة تستند إلى آراء (مفهوم وتفسير) للجهات الفاعلة في موقع تهاء البحث. لذلك، تستخدم هذه الدراسة منهج البحث الكيفي بنوع دراسة حالة للمساعدة في استكشاف وجود غرس الاعتدال الديني ومساهمته في تعليم التربية

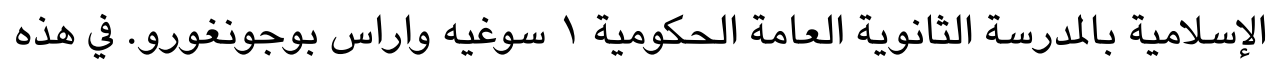


الدراسة، وجود الباحث كأداة رئيسية للبحث من أجل فهم طبيعي للواقع الموجود

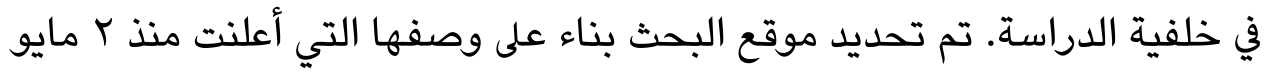

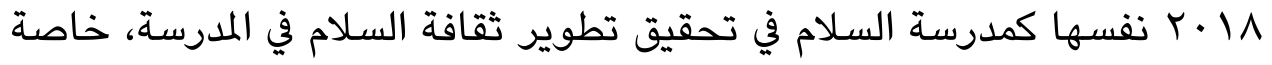
في مادة التربية الإسلامية والأخلاق. تتكون مصادر البيانات الرئيسية في هذا البحث

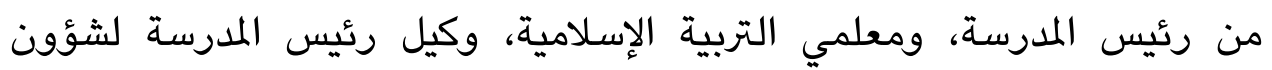
الطلاب، والطلبة وأصحاب المصلحة الآخرين. البيانات التي تم الحصول عليها من خلال المنال المقابلة والوثائق والملاحظة (2009 Miles and Huberman). وتم جمع البيانات وتحليلها بطريقة

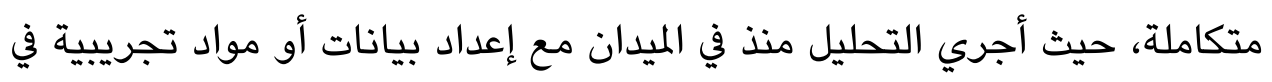

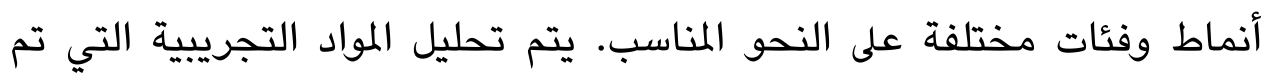

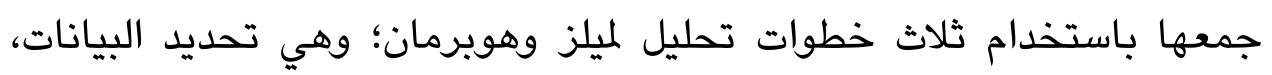

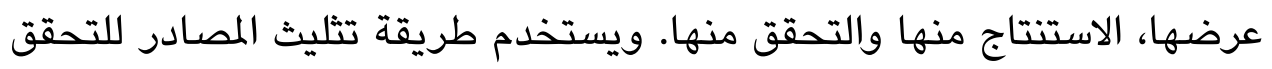
من صحة البيانات، حيث تمت مقارنة البيانات التي تم الحصول عليات اليها من رئيس

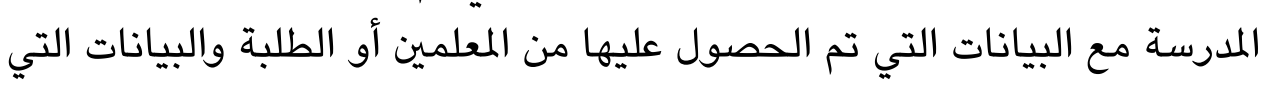

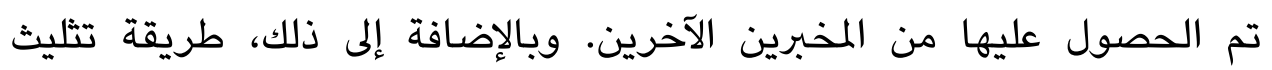

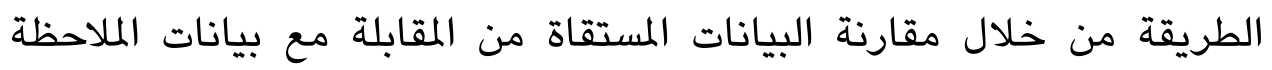

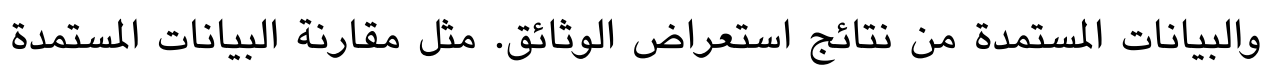
من المنهج الدراسي وخطة التدريس مع البيانات المستقاة من منات ملاحظات المنات الأنشطة

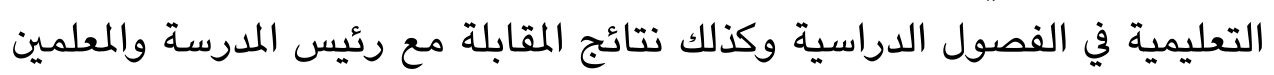
والطلبة.

\section{غرس الاعتدال الديني لمكافحة التطرف الافت الدرن}

بعض صور غرس الاعتدال الديني في تعليم التربية الإسلامية بالمدرسة المافية المانية

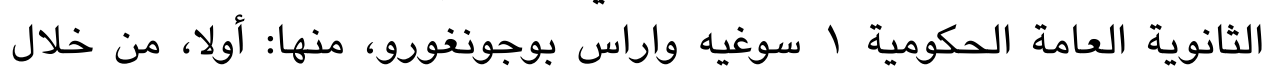

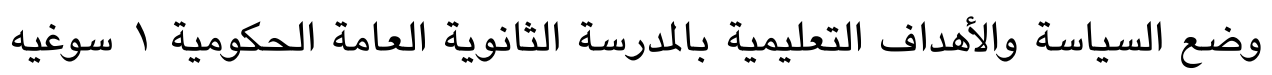

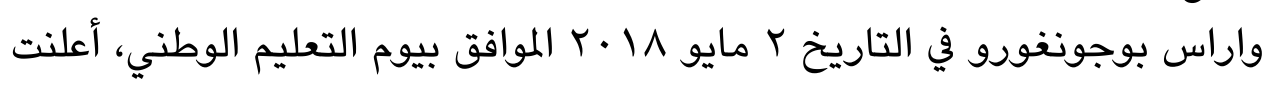

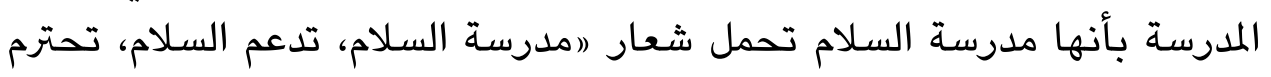


الاختلاف وتحافظ على العلاقات الأخوية بين الطلبة). كما شارك العديد من أصحاب المصلحة، بمن فيهم رئيس مكتب وزارة الشؤون الدينية في مقاطعة

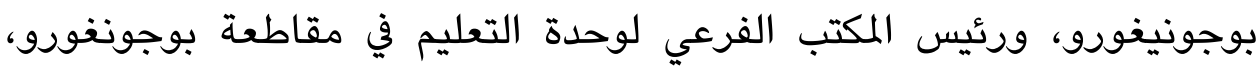
ورئيس المكتب الشرطي سوغيه واراس، ورئيس المكتب العسكري سوغيه واراس، ورئيس مقاطعة سوغيه واراس كضيوف مدعوين في برنامج إعلان مدرسة السلام.

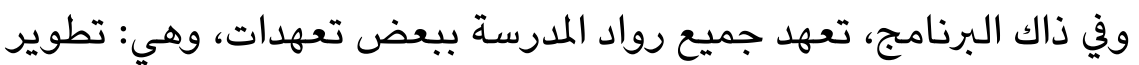

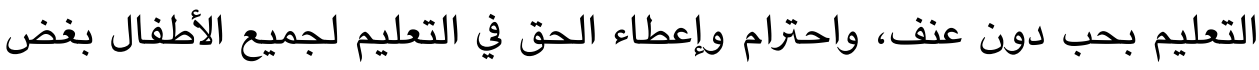

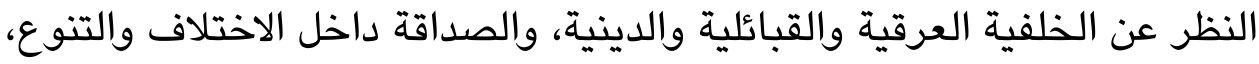
والحفاظ على حالة السلام؛ دعم السلام واحترام الاختلاف والحفاظ على العلاقات الأخوية في بيئة تعليمية (Sondang 2018).

في سياق تعليم التربية الإسلامية بالملدرسة الثانوية العامة الحكومية الماهية سوغيه واراس، رسالة السلام وقيمة الاعتدال مدعومة من سياسي الاعتراف الافيه

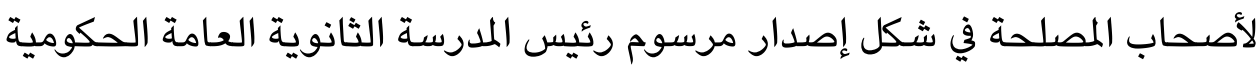

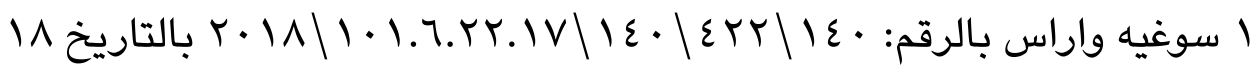

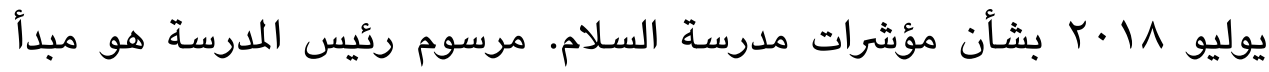
توجيهي لبناء فهم الإسلام الوسطي في البيئة المدرسية. وتشمل تلك ملك المؤشرات التهات تحقيق العلاقات الاجتماعية والتفاعل بين المتدينين الذين هم متسامحون حتى يتم

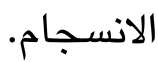

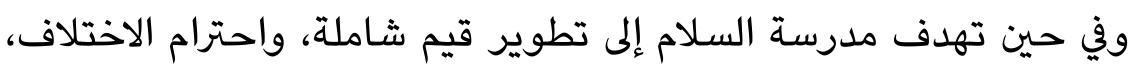

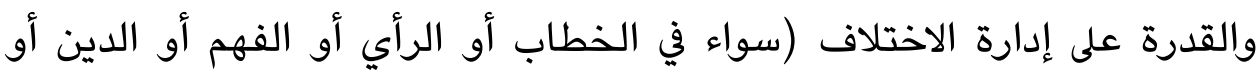
الجماعة أو الاعتقاد، الاجتماع والاقتصاد)، واحتراء الاحام التنوع أو التعداد بشكل

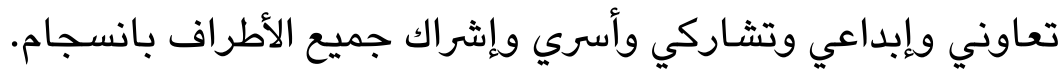

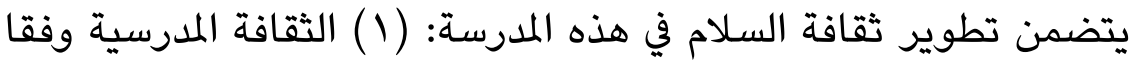

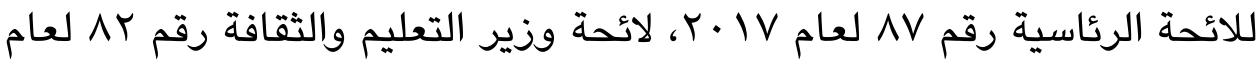

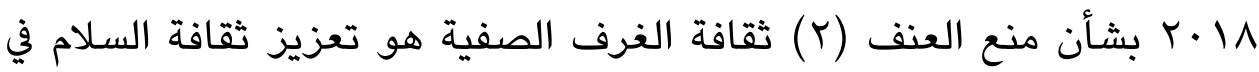
الفصول الدراسية من خلال عملية التدريس والتعلم. تم تصميم التعليم في 


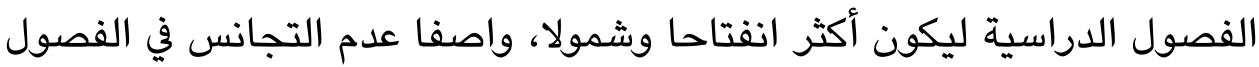

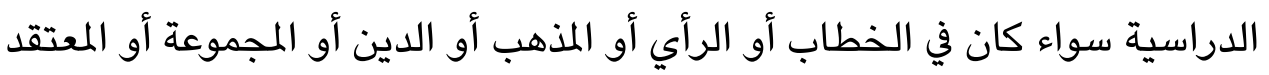

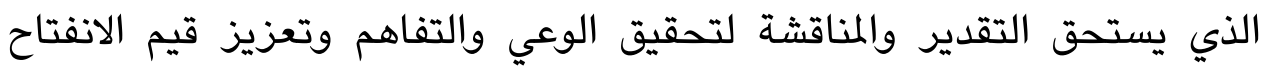

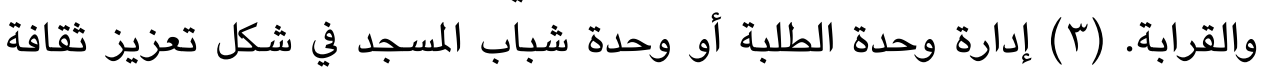

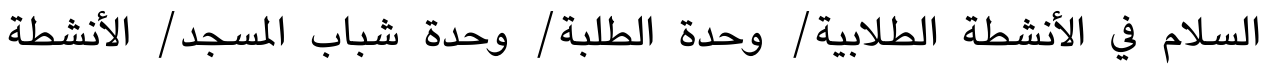

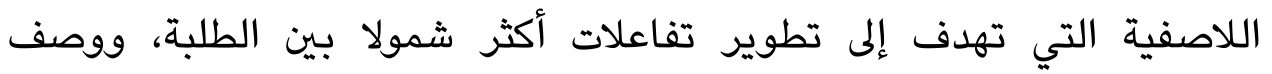

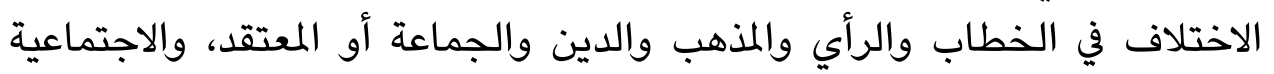

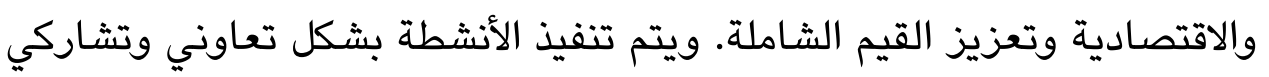
وإبداعي وإثراك فيها جميع الطلبة لبناء العلاقات الأسرية. للمدرسة الثانوية العامة الحكومية الثانية سوغيه واراس رؤية، ورسالة،

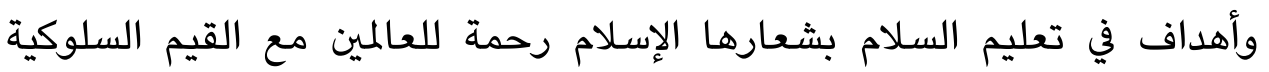

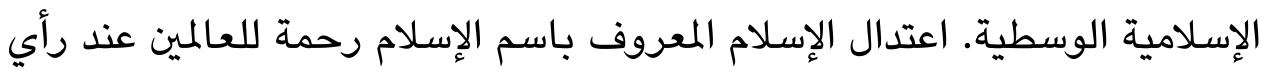

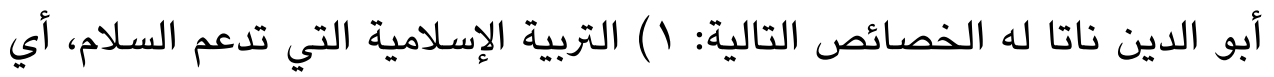

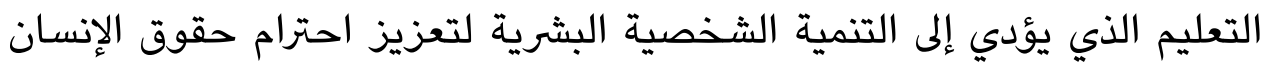

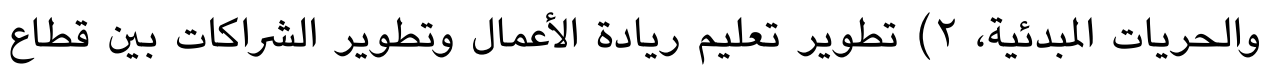

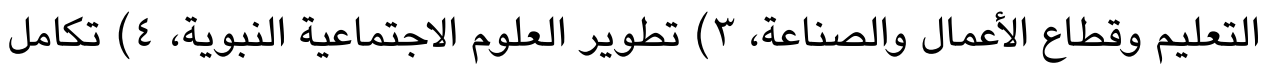

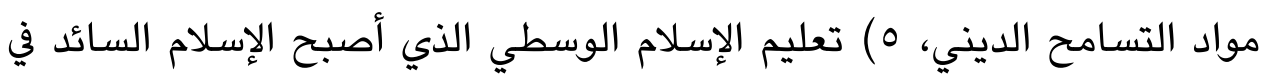

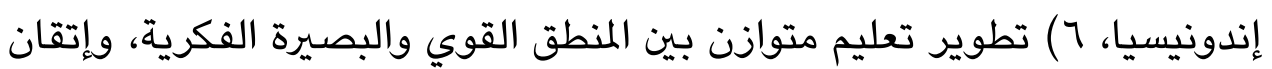

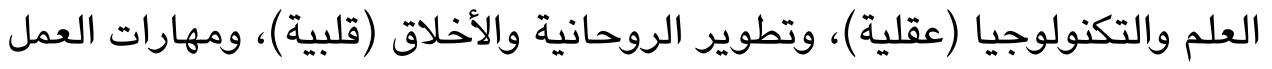

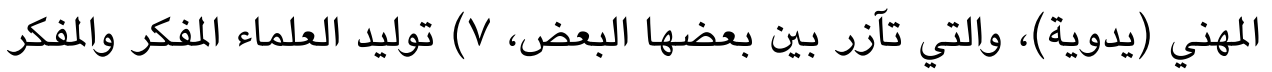

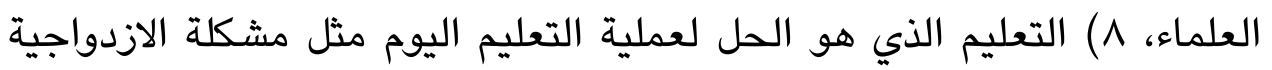

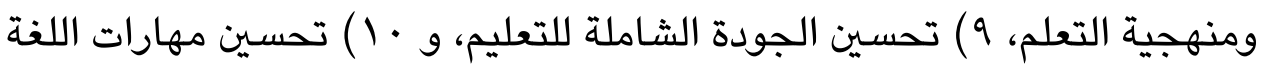
الأجنبية، وخاصة الإنجليزية والعربية (Nata 2016).

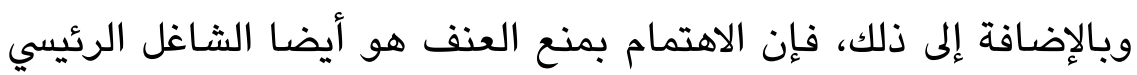

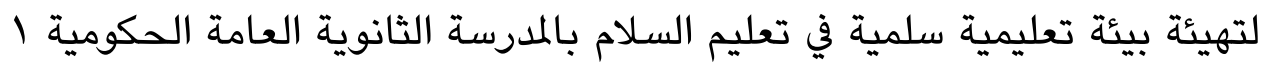
سوغيه واراس الذي يتكامل مع المناهج الدراسية. إن تصميم المدرسة على سياسة 
السلام ومضمون القيم الإسلامية المعتدلة في المدرسة الثانوية العامة الحكومية التها سوغيه واراس التي تسيطر عليها مباشرة رئيس المدرسة ومؤسسة واحد هو

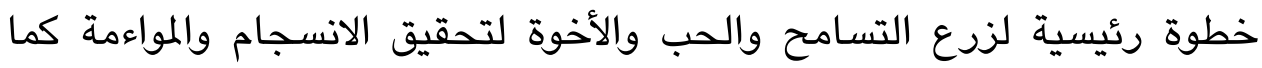
يحلم حتى الآن.

ثانيا، المنهج الدراسي المكتوب (المقرر/المقصود) ـيفهم من المنهج الدراسي

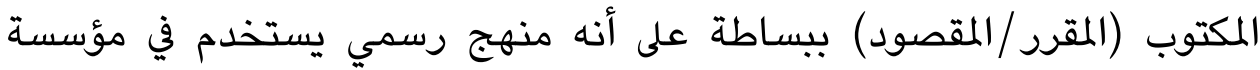

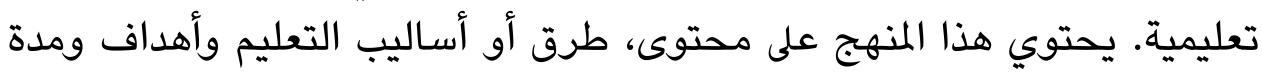

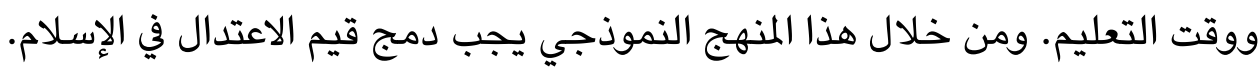

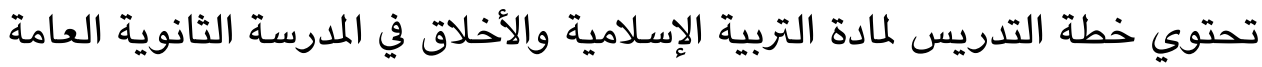
الحكومية ا سوغيه واراس على القيم الإسلامية التي تكون رحمة للعالمين والقيم

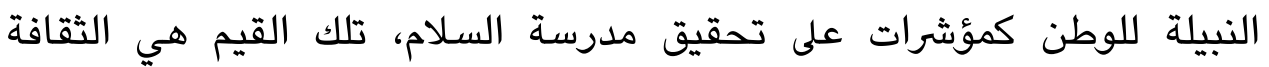

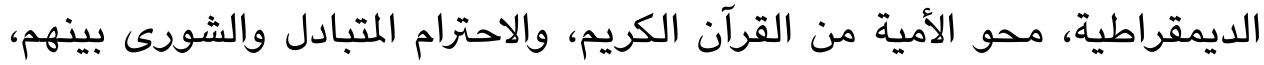

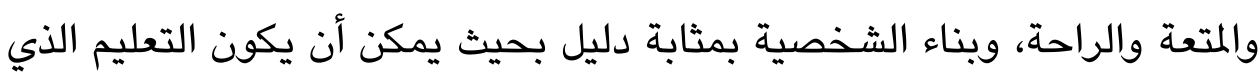

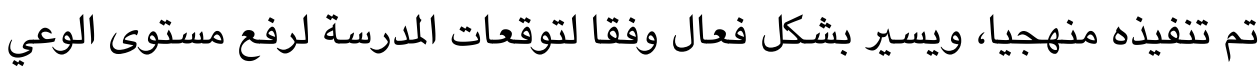

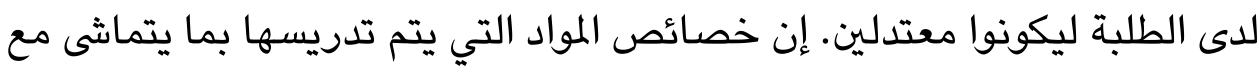
قيم التعاليم الدينية والاجتماعية والثقافية والتعددية الإندونيسية مهمة للغاية

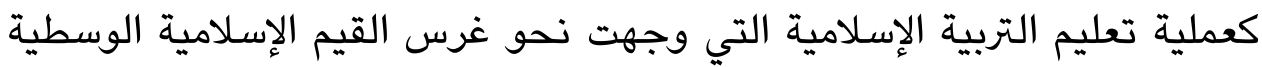
المحبة للسلام (Rozi 2019).

الكفاءة المستهدفة التي يتمتع بها الطلبة بعد تعلم مادة التربية الإسلامية والأخلاق هي أن الطلبة تادرون على التصرف بانضباط، ودعم الصدق، والاهتمام

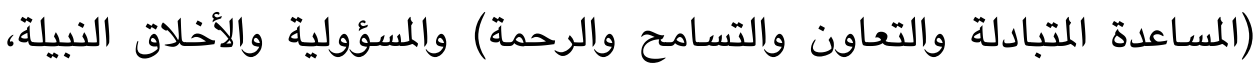
حيث تكون من القيم الأساسية للتعليم التعددي متعدد الثقافات في تطوير المواقف الإسلامية الوسطية. تذكرنا هذه النتيجة برأي محمد علي أن هدف التربية الإسلامية التهدية لا ينحصر على تحسين الإيمان والتقوى، بل تزويد الطلبة بالمعارف عن تعددية

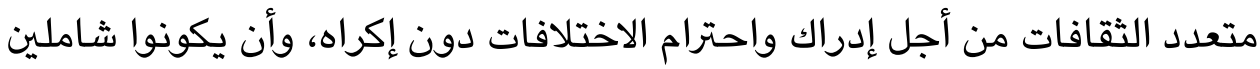
ومتواصلين، وألا يشكوا في بعضهم البعض. ويالإضافة إلى ذلك، فإن اتباع المنهرج 
المعتدل والودي في الدين لا يعني أن الطلبة يمكنهم ممارسة الدين بحرية وفقا

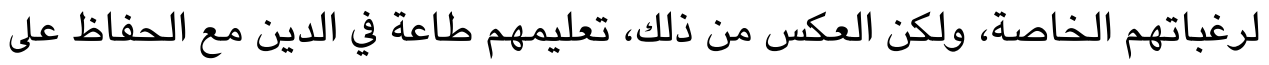
هوياتهم الدينية بمسؤولية تامة (Ali 2003).

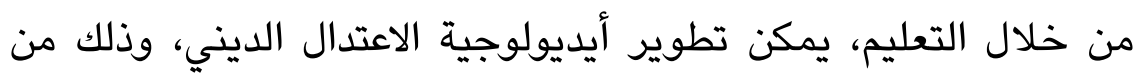
خلال تحسين عدة جوانب بحيث يمكن تحقيق عملية غرس القيم الإسلامية الوسطية كما تم تخطيطها. في مجال التطبيق، يطرح كاسينيو هارتو مفهوم

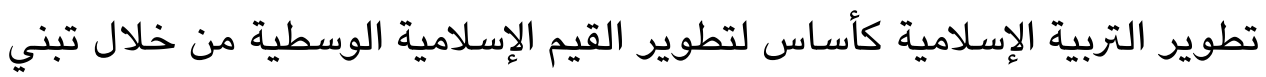

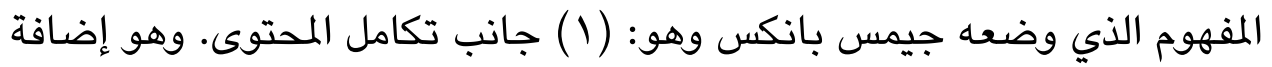

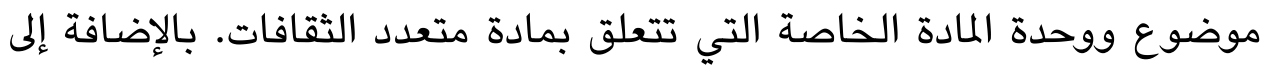
ذلك، يجب أن تعكس المادة وجهة النظر ومنظوة المادة النورا متنوعا.

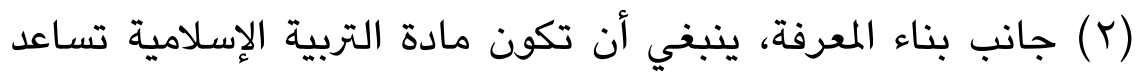
الطلبة على فهم وجهات النظر وصياغة الاستنتاجات التي تتأثر بمسيرتهم المعرفية. (ب) جانب الاقتصار من التحيز، يسعى معلمو التربية الإسلامية إلى اتباع طريقة وأساليب متطورة ومختلفة حتى يكون الطلبة منفتحين وإيجابيين في معني مواجهة الاختلافات. (ع) ينبخي أن تتضمن مادة التربية الإسلامية أبعاد التعليم

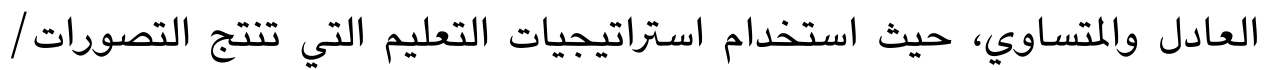
الآراء أو السلوكيات التي هي عادلة ومتساوية. مثل نموذج التعليم التعاوني،

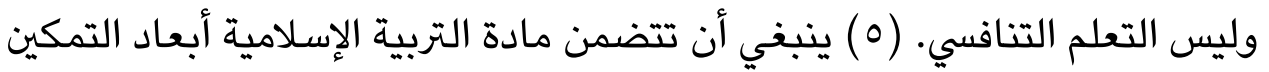

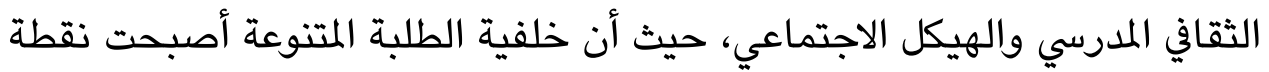
هامة يديرها معلمو التربية الإسلامية بشكل جيد كمادة لبناء الثقافة الملدرسية

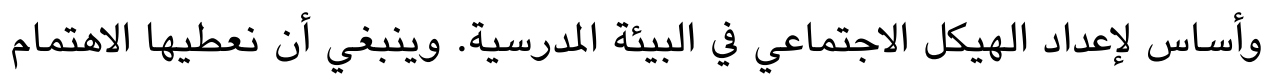

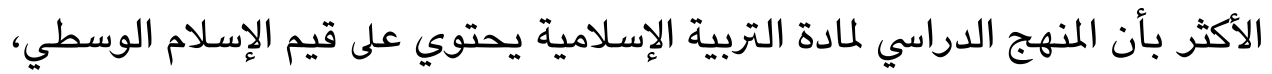

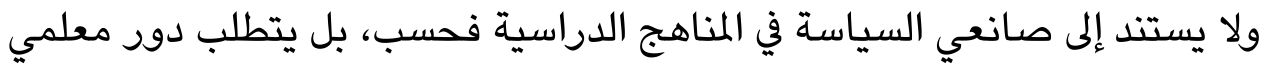
التربية الإسلامية في ترجمة تلك الرؤى في سياق تعليم الإسلام الوسطي الحقيقي.

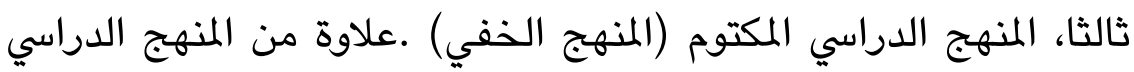
الرسمي، يمكن لمعلمي التربية الإسلامية أن يطوروا عمليتهم التعليمية بالمنهج 
الدراسي المكتوم في عملية غرس الاعتدال الديني. يفهم من المنهج المكتوم وفقا

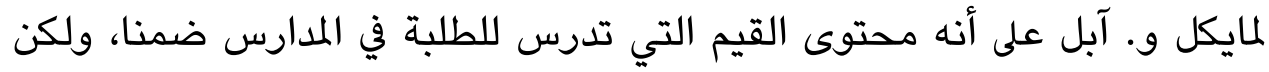

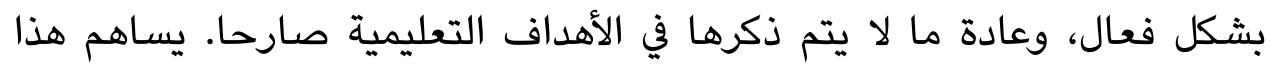
المنهج الدراسي بشكل كبير في الجهود الرامية إلى الحفاظ على دلى الأيديولوجية مهيمنا (Michael W. Apple in Hermawan 2020)

عند دراسة المزيد، فإن محتوى المنهج الدراسي في مادة التربية الإسلامية في المدرسة الثانوية العامة الحكومية ا سوغيه واراس يتوافق مع قيم الإسلام رحمة

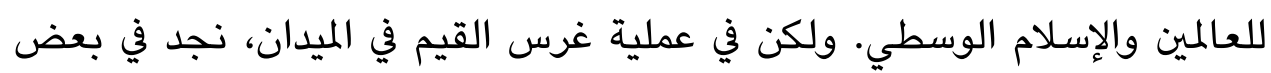
الأحيان عدة الطرق لاستكشاف قيمة الإسلام الوسطي خارج المناهج الرسمية دون فون

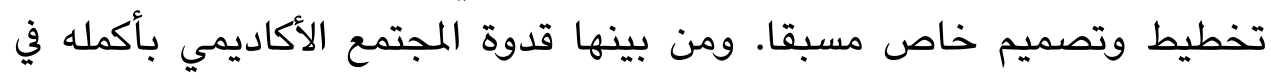
المدرسة الثانوية العامة الحكومية ا سوغيه واراس عند بناء سياق البيئة المدرسية التي تدعم تطبيق القيم الإسلامية الوسطية مثل زيادة الإيمان والتقوى لله سيحانه وتعالى. إن التحقيق للسلوك الوسطي لدى معلمي التربية الإسلامية هو قدوة مهمة للطلبة. وفقا لبيان أحد معلمي التربية الإسلامية (يني نور شمسية، نتيجة المقابلة،

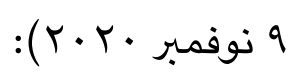

"اتوجيه وإرشاد الطلبة للتعويد على الصلوات الخمس بالجماعة.. وعندما تنتهي

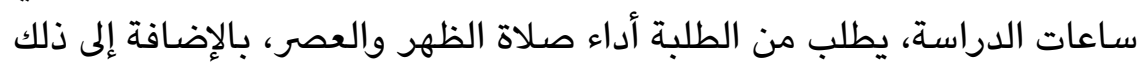

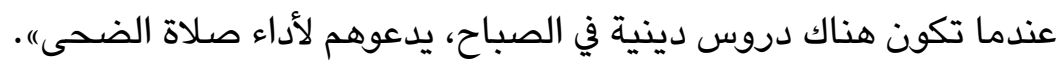

في سياق إندونيسيا والدين، معلمو التربية الإسلامية هم مصدر للمعرفة

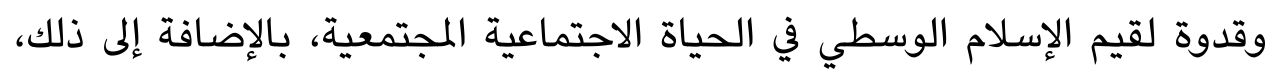

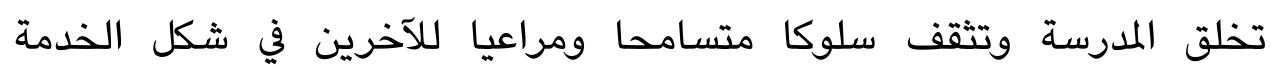
الاجتماعية التي يتم تنفيذها دوريا في هذه المدرسة. وكما ذكر معلم التربية الإسلامية الذي عين وكيلا لشؤون الطلاب: (محمد مصباح الفؤاد، نتيجة المقابلة 9 نوفمبر • · · Y): (من خلال إعطاء الفهم للطلبة، ليكونوا أكثر اهتماما اجتماعيا،

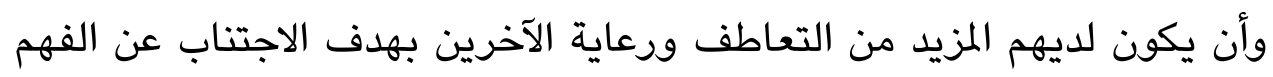
الجذري الذي يمكن الحصول عليه). 
إن جو المدرسة التي تخلق وتثقف سلوكا متسامحا ومراعيا للآخرين في الآني إنيا

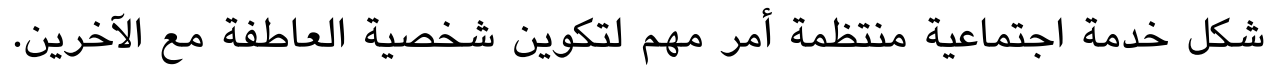
عندما راجعنا إلى جانب عرض مادة التربية الإسلامية، نقل المعلمون المادة المادية

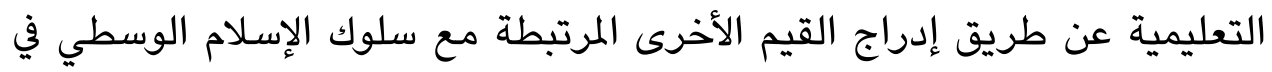

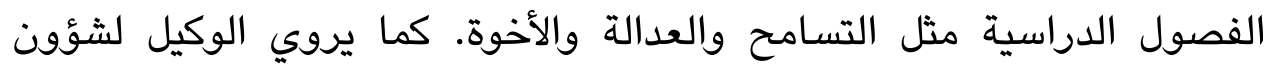

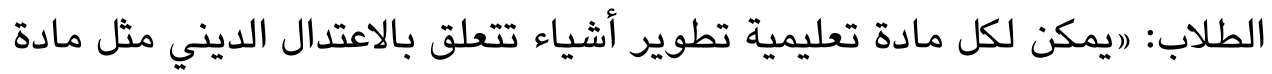

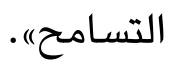

$$
\text { مؤيدا لما قبله، قالت يني نور شمسية: }
$$

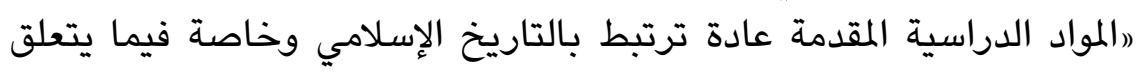

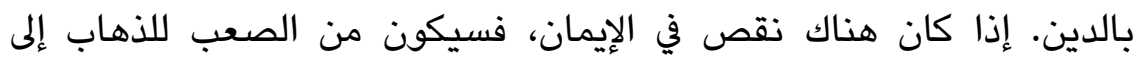

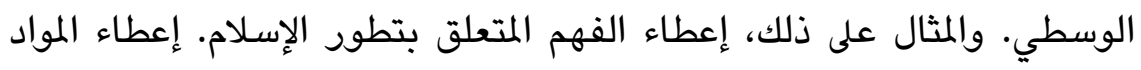
المتعلقة بالاعتدال الديني مثل وضع مخطط بين المفهوم الليبرالي والراديكالي،.

المواد الإضافية التي تدرس خارج المنهج الدراسي المكتوب، ولكن ترتبط

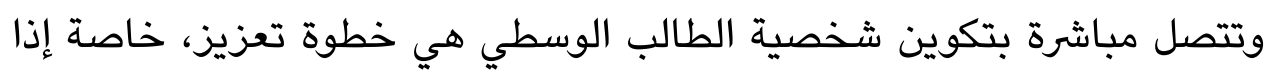

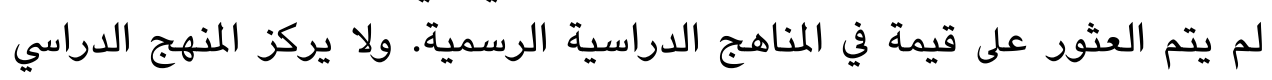

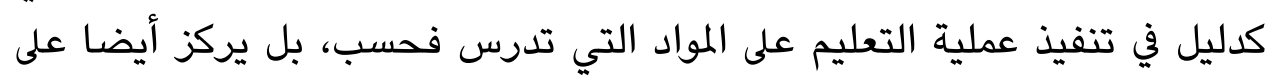

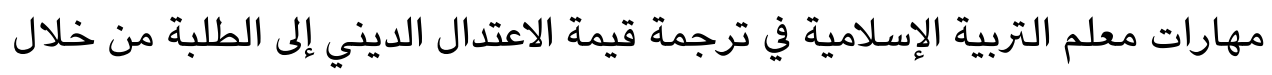

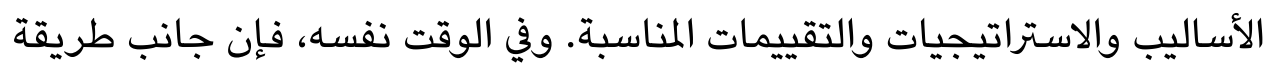

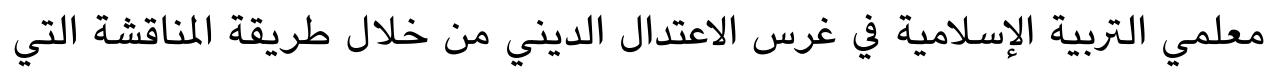

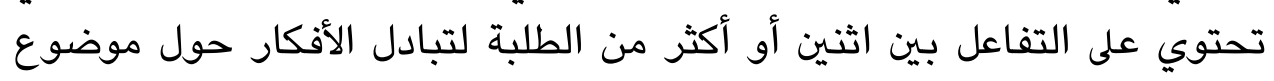

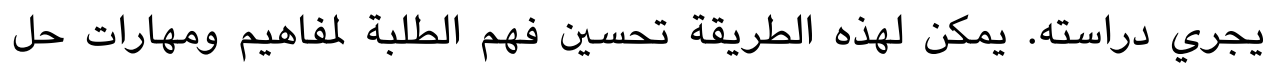

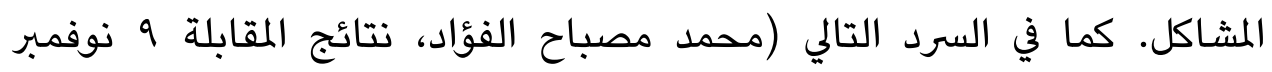

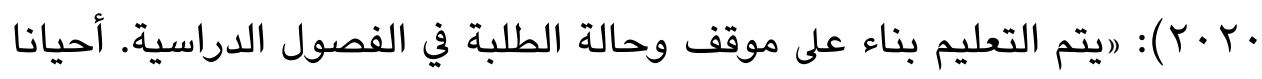
يكون التعليم التعاوني أو التناقشي، لأنه يعلمهم احترام اختلاف الآناء بـاء بعضهم

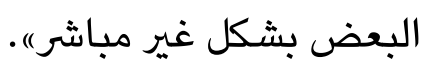


بالإضافة إلى ذلك، ولصقل الثقافة الاجتماعية للثقافات والأديان المختلفة، تمت دعوة الطلبة لملاحظة ومناقشة مباشرة من خلال طريقة جولة الدراسة. أي

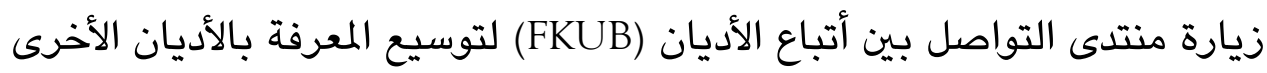

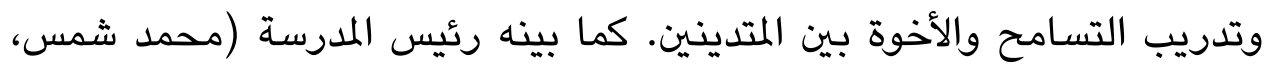

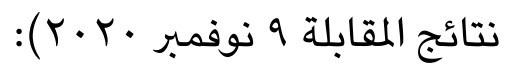
"برنامج مدرسة السلام هو من إحدى العلامات التجارية في تعزيز الشخصية. وفي هذا البرنامج هناك العديد من الأنشطة أو البرامج أحدها هو الحئام الاعتدال

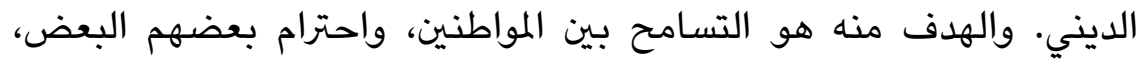

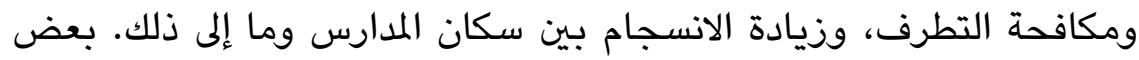

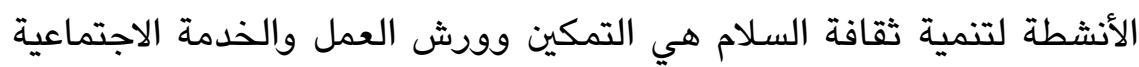
وصلة الرحم مع منتدى التواصل بين أتباع الأديان بهدف وفئ زيادة الوعي

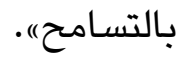

ويمكن الحصول على مواقف الطلبة المنفتحة على الاختلافات من خلال عملية التدريس والتعلم، أي قدرتهم على التفكير في احترام حق الآخرين في الحياة، مثل الحق في التعليم والتعبير والدين وعدم التسرع في إلقاء اللوم على الآخرين.

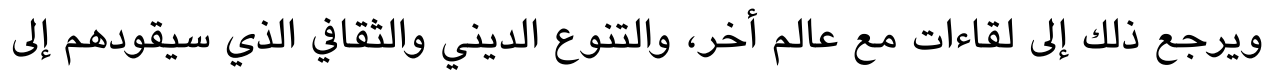

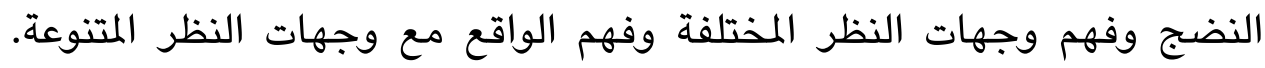

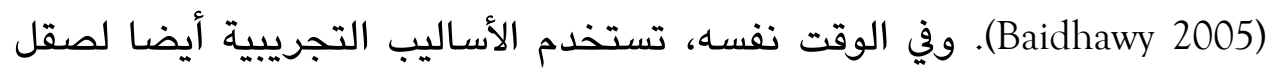
المنطق النقدي للطلبة فيما يتعلق بالارتباط بين المواد وتنفيذها في الحياة اليومية. وذلك في شكل إعطاءهم الفرصة للبحث الذاتي بمراقبة كائن، وتحليل، واستنتاج

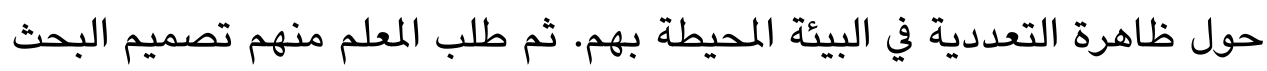
الميداني، وعرضه أمام الصف. علاوة على ذلك، يلعب معلمو التربية الإسلامية دورا

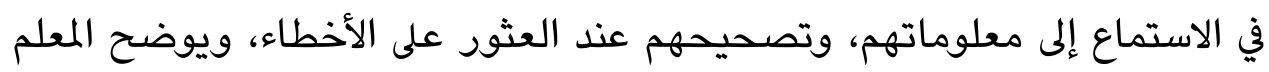
بالفهم الصحيح. كما بين الوكيل لشؤون الطلاب ومعلم التربية الإسلامية:

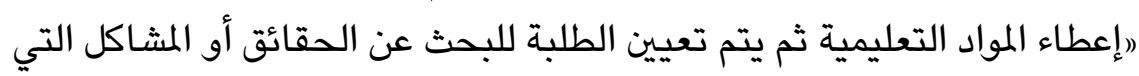

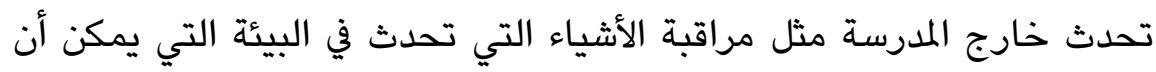


يكون لها تأثير على قيمة الحكم. على سبيل المثال في الزكاة، بعض الطلبة يشتري

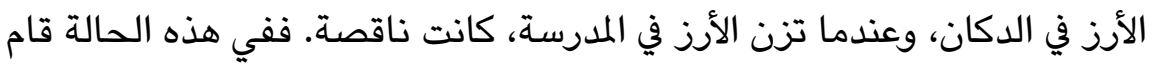

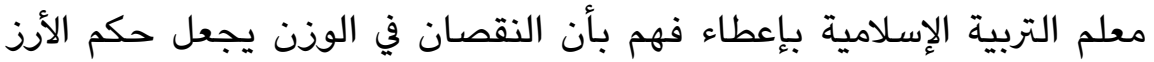
صدقة، وذلك يتأثر على قيمة الحكم. ويالإضافة إلى ذلك، فإنه يوفر التعليم وفقاء

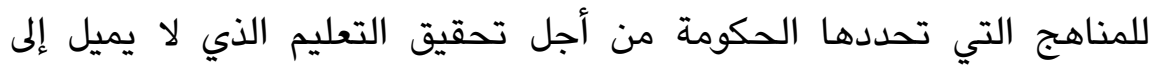
مجموعة معينة).

من الناحية المثالية، يمكن قياس غرس الإسلام الوسطي من خلال

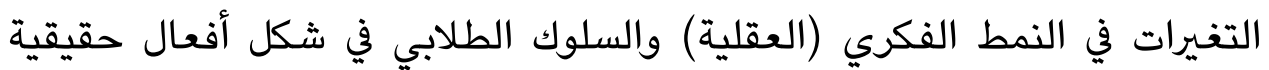
كمسلم وسطي. تقييم قيمة الاعتدال الديني ليس بالأمر السهل بالنظر إلى أن العاطفة تتأثر ذاتيا بتجربة الطلبة الشخصية وفهمهم وتقديرهم للاعتدال الديني. فهم الطلاب وشغفهم بالاعتدال الديني عملية طويلة ومستدامة، لأن البشر طوال حياتهم لا ينفصلون عن واقع الثقافة بمتعدد الثقافات التي تتطلب فهم أنفسهم

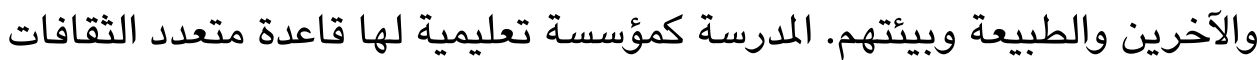
من المهم جدا لتطوير موقف وسطي لدى الطلبة في التدين لتعزيز الجيل المستقبل الذي يمتلك شخصية قوية ومتسامحة ومنفتحة على الاختلافات.

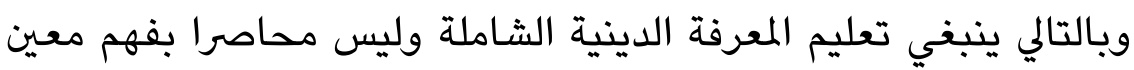

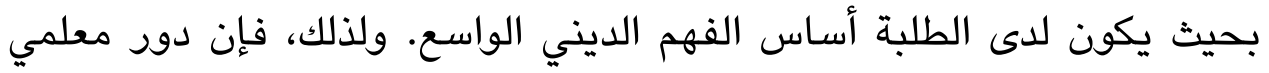

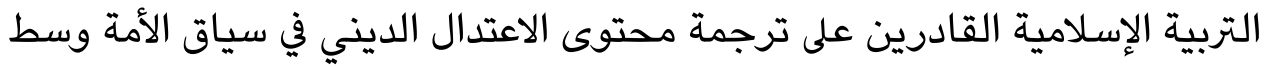

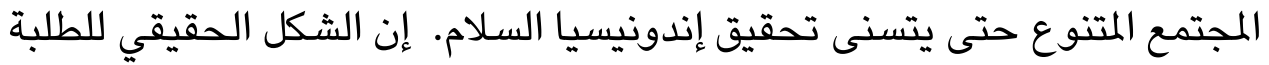
الذين يفهون معنى الإسلام الوسطي لا تثيرهم دعاية ضد الاعتدال الديني بسهولة.

لا تقتصر عملية التعليم داخل الفصول الدراسية، لأن غرس قيم الإسلام

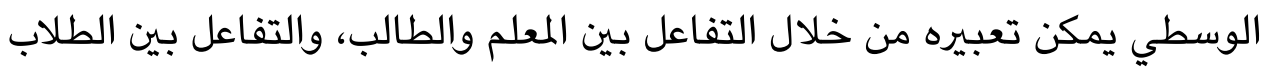

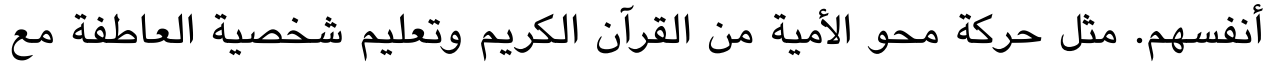

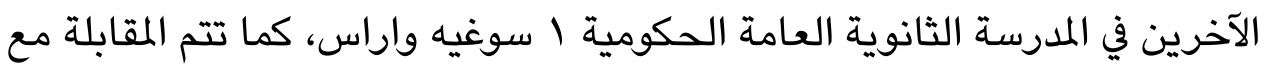

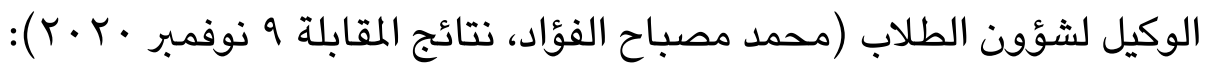




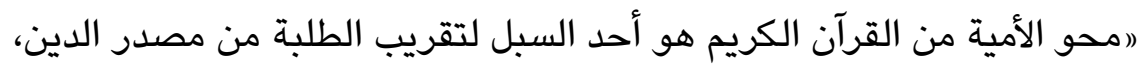

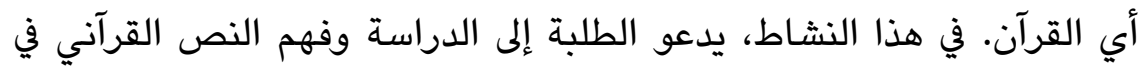

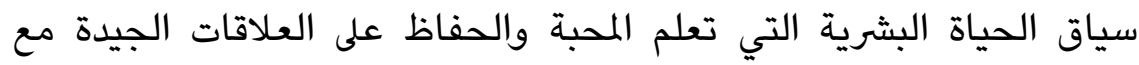

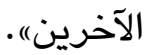

وفي هذا الصدد، ترى يني واحد، مديرة مؤسسة واحد، هناك عدة العوامل

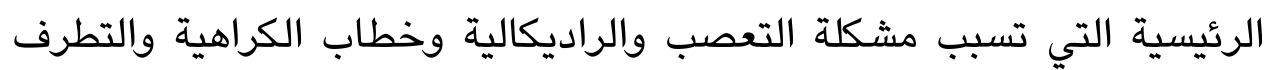

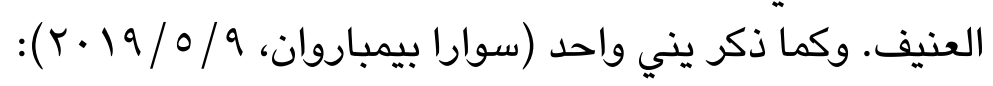

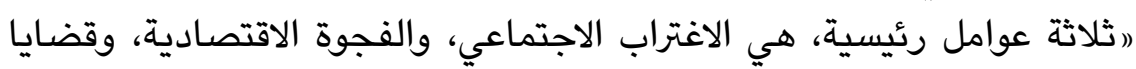

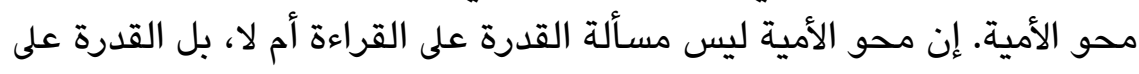

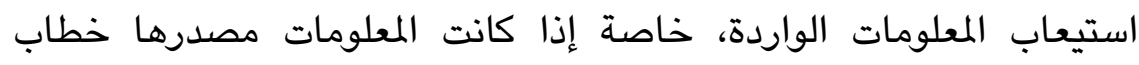
ديني"

محو الأمية من القرآن الكريم هو أحد السبل لتحسين الفهم الشامل

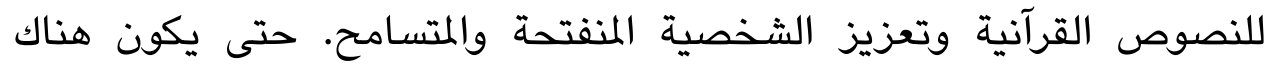

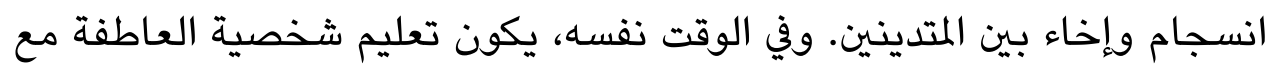

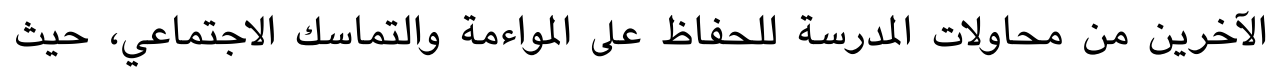

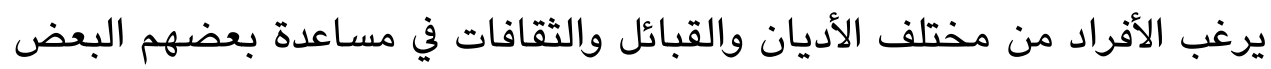

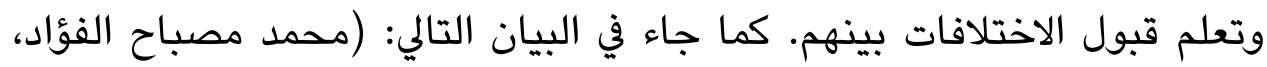

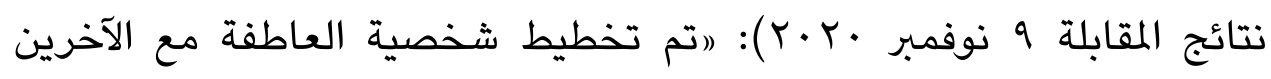

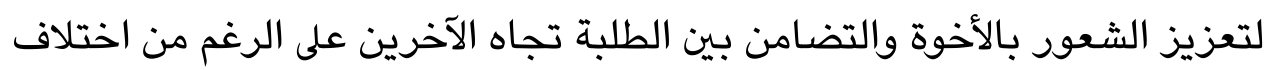

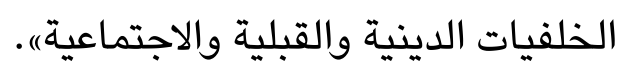

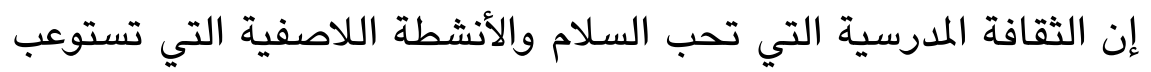

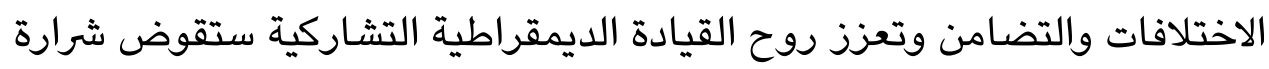
الاحتكاك والعنف التي قد تحدث بسبب الإساءة بين الجماعات. بناء الاعتدال

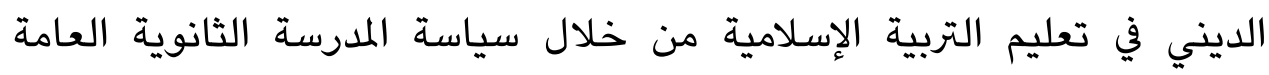

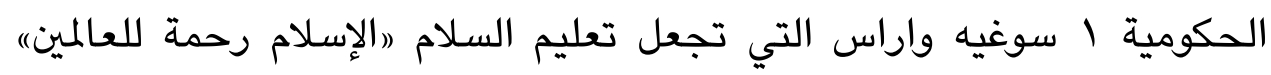


صراحة في المناهج الدراسية والمناهج المكتوم كدعم إيجابي. وفي هذا السياق، ذكر برك

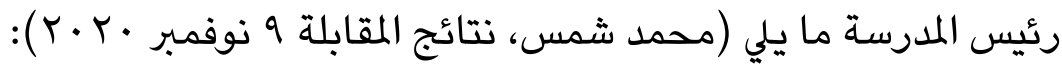

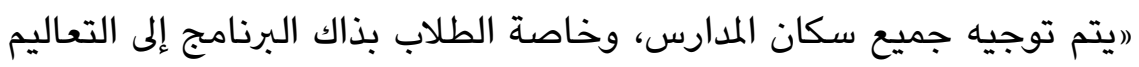

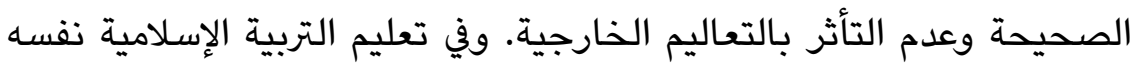

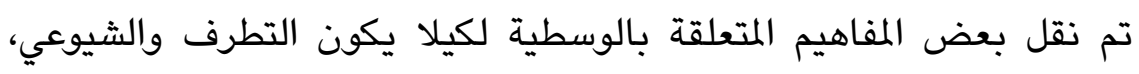

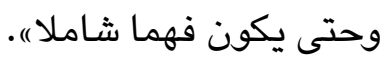

وفي الوقت نفسه، وفقا لما قاله معلم التربية الإسلامية وكذلك الوكيل

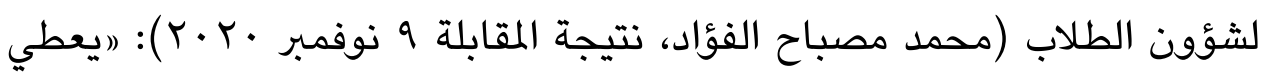

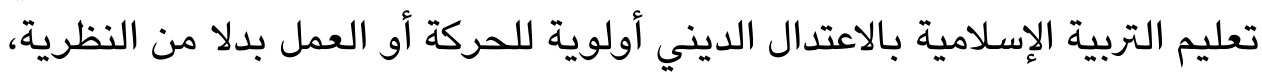

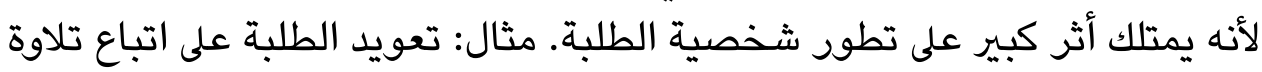

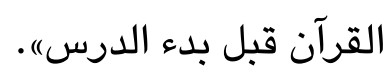

ويتماشى مع البيان أعلاه، قول معلمة التربية الإسلامية يني نور شمسية

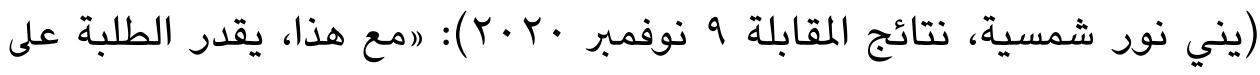

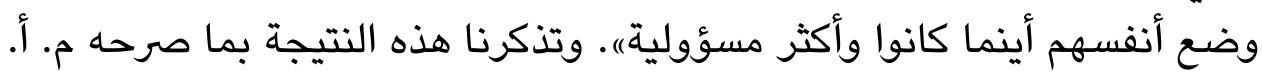

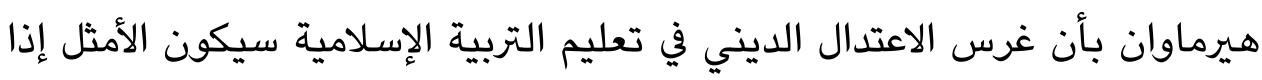

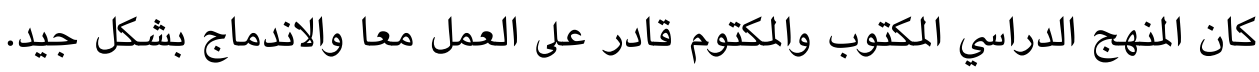

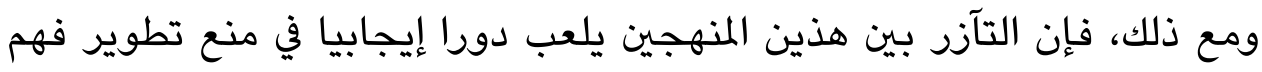
الإسلام الليبرالي والراديكالي وغير متسامح.

\section{مساهمة الاعتدال الديني في تعليم التربية الإسلامية في المدرسة الثانوية

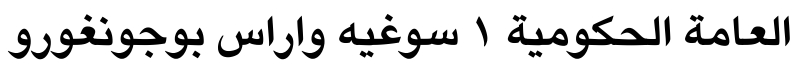

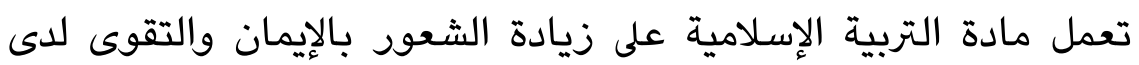

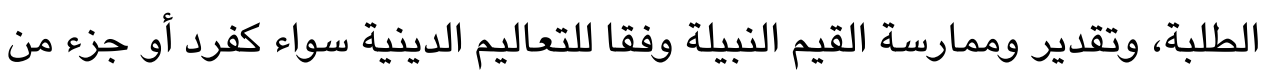

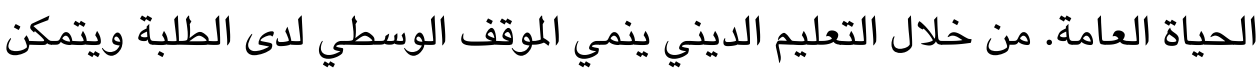

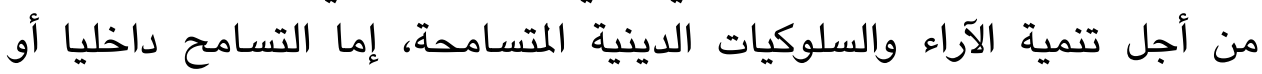

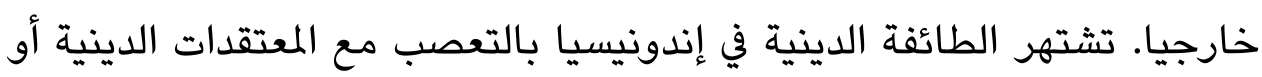


العقيدة. لذا، تعطى الأولوية للمنهج الديني لغرس الوعي بالتعددية في المجتمع بمتعدد الثقافات لتحقيق الانسجام بين المتدينين. يكون الاعتدال الديني الذي يظهر القيم الإسلامية الوسطية والودية

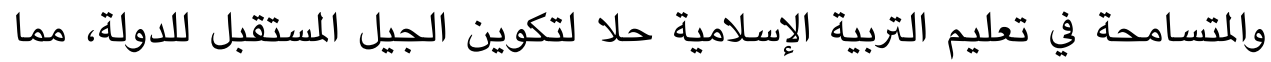

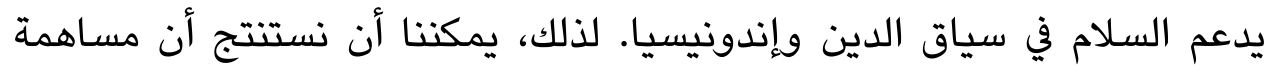

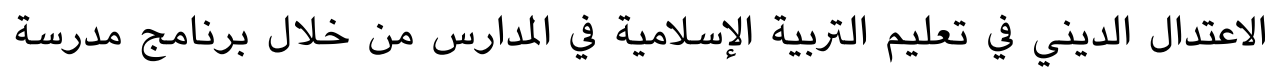

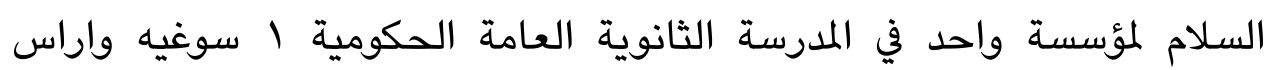

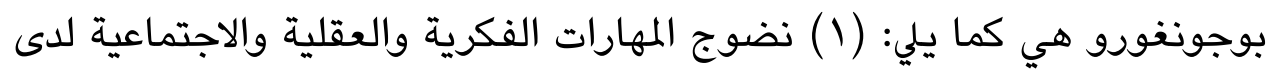

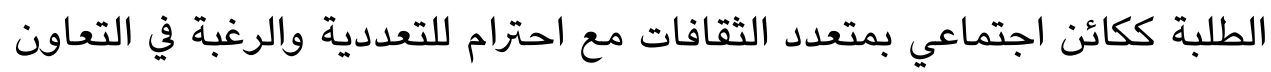

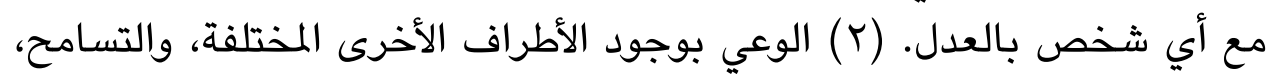

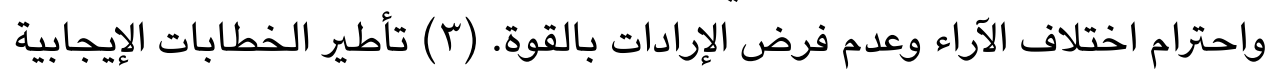

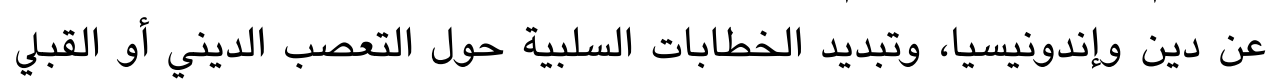

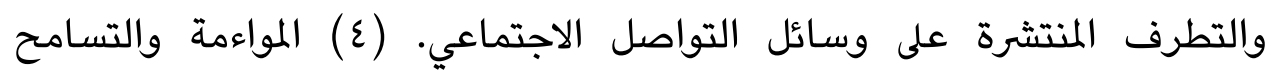

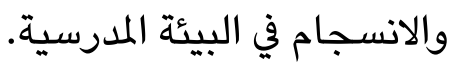

\section{الاعتدال الديني في تعليم التربية الإسلامية لمكافحة التطرف}

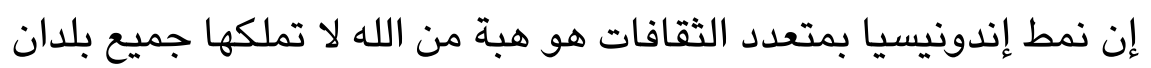

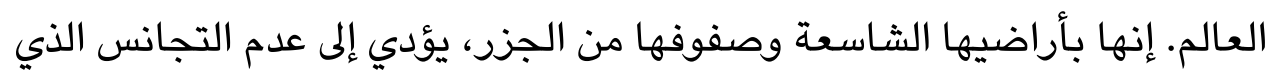

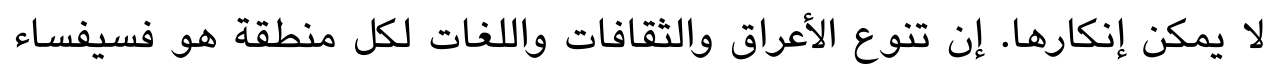

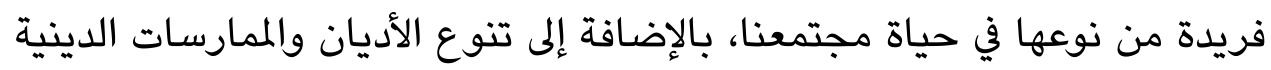

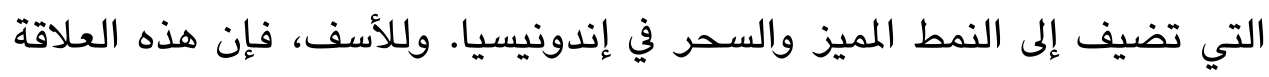

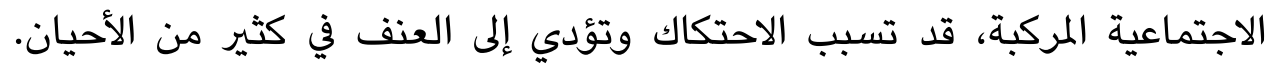

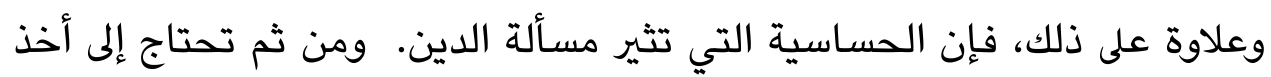

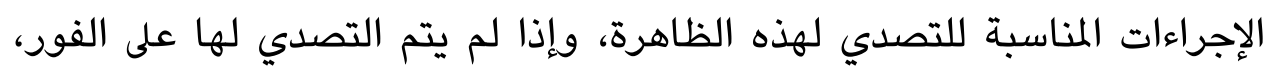
فإنها ستكون قنبلة موقوتة يمكن إشعالها في أي وقت (Clark 2006).

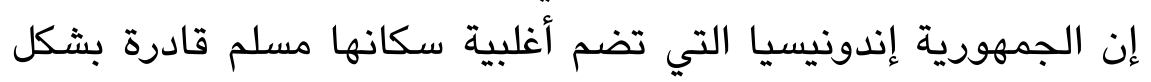
مثالي على تخفيف روح الإسلام باعتبارها تعاليم السلام والوسطية أنية في العملية 
التعليمية. وينبني تعزيز المواقف الدينية الوسطية بصورة منهجية لمنع نمو التواتيكا

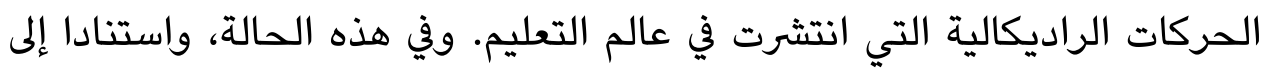

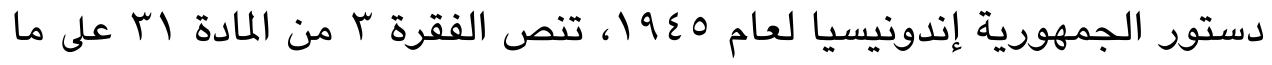

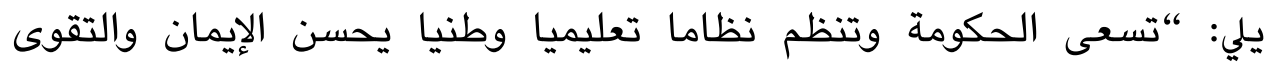

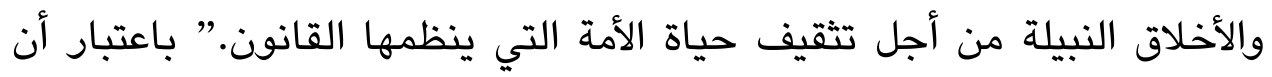

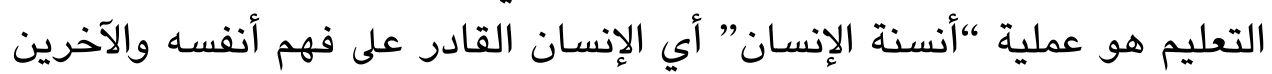
والطبيعة والبيئة الثقافية المحيطة به (الانهان" (Driyarkara 1980).

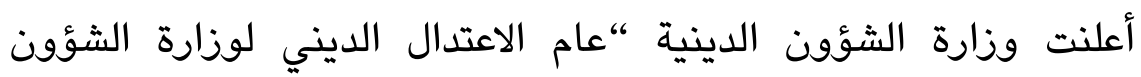

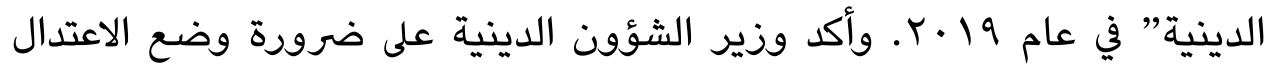

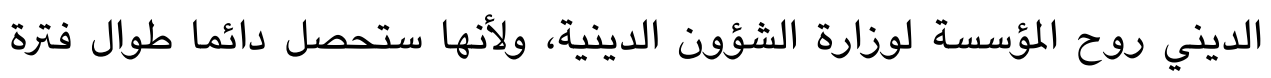

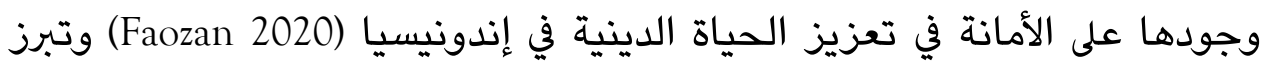

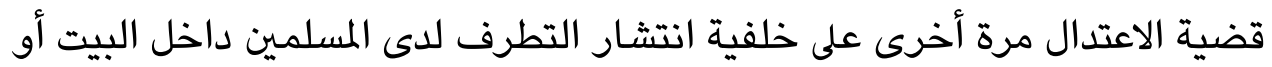
خارجه. وفي هذا الصدد، اكتسب الاعتدال جاذبية متجددة داخل التهل المجتمعات التهات

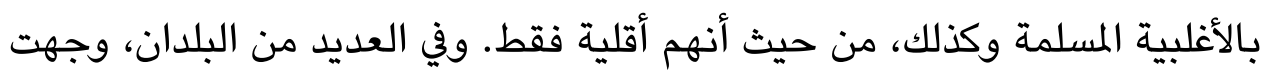

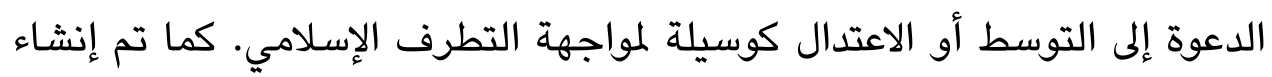

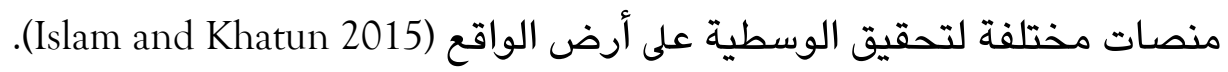

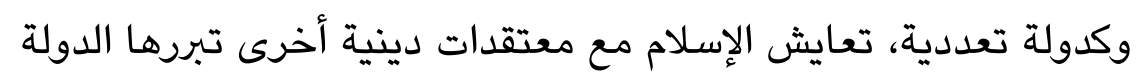

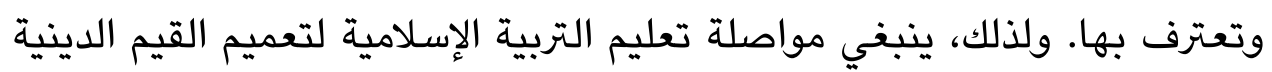

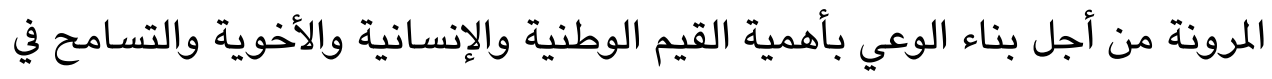

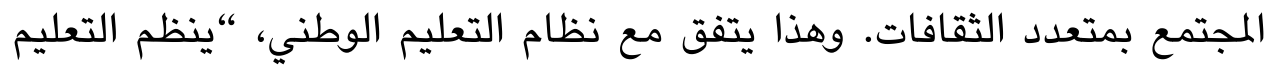

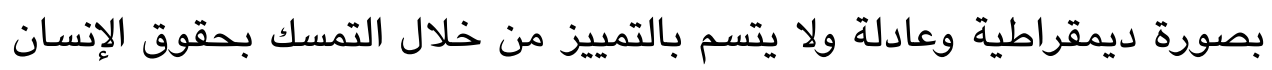

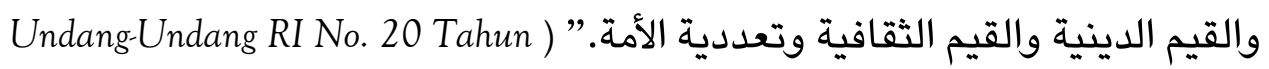
2003 Tentang Sistem Pendidikan Nasional, 2006 وتثار قضية الاعتدال الديني بشكل متزايد حيث يتهم المجتمع العالمي

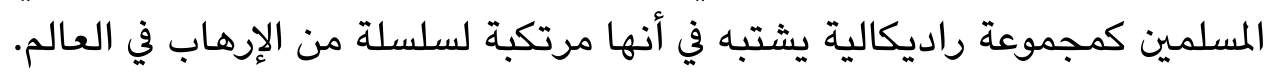

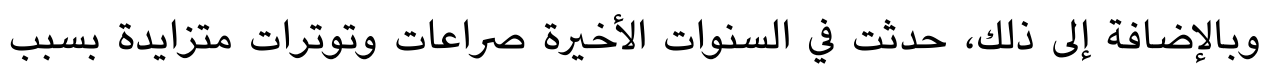


عدم التسامح بين المتدينين. ويتوقع من قطاع التعليم كمؤسسة أن تكون قادرة

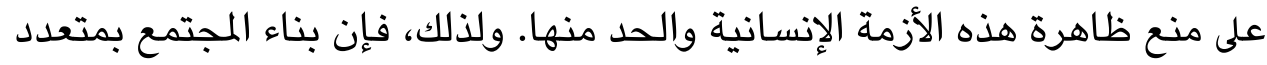
الثقافات بمنهج الاعتدال الديني في المؤسسات التعليمية أمر بالغ الأهمية. وفي هذا السياق، ذكر أزوماردي أزرا أن التعليم، بما في ذلك الكئكية تعليم التربية

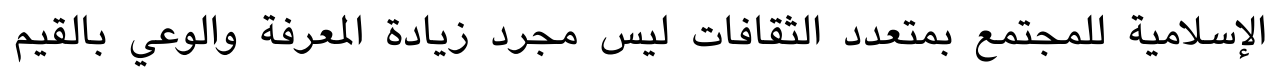

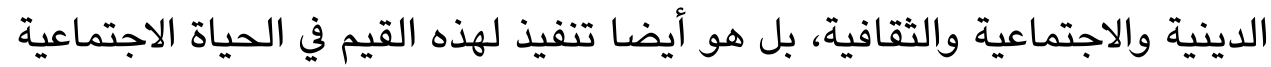
والوطنية (Azra 2007). وفي الوقت نفسه، يرى كورتيس ثلاثة مجالات للقدرة الاجتماعية التي يجب امتلاكها في حياة الناس غير المتجانس، وهي: الانتماء

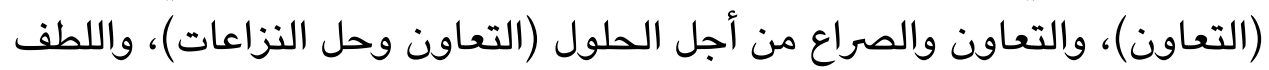
والرعاية والمودة / المحبة (الودية، والرعاية، والمحبة) (Akhmadi 2019).

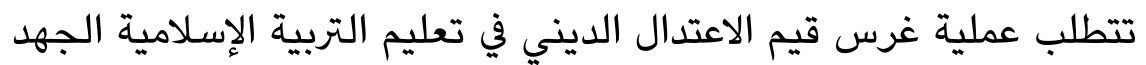
الكبير لجعل تغيير الأفكار والآثار الحقيقية لفهم الإسلام الوسطي الذي يظهر من لاعني

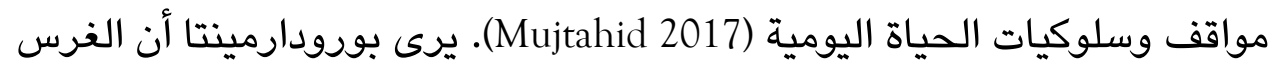

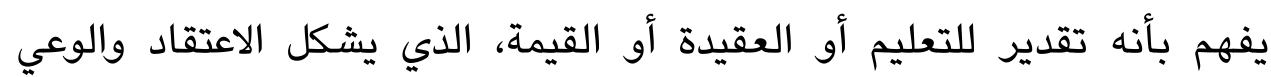

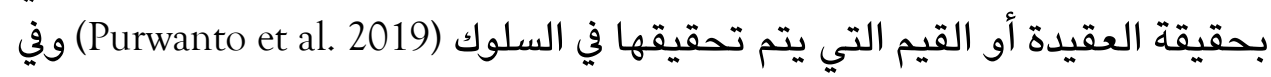
الوقت نفسه، يقول أسيف: إن مرحلة غرس قيم الإسلام الوسطي للطلبة تكون من

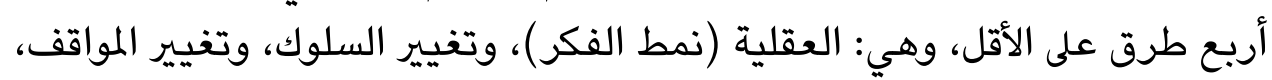
وتغيير المجتمع (التغيير الاجتماعي والثقافي) (Azra 2007). الوسطية (الفهم الاعتدالي) هي إحدى خصائص الإسلام التي لا تملكها الديانات الأخرى. وهي تدعو إلى الإسلام المتسامح ضد جميع أشكال الإلى الليبرالية

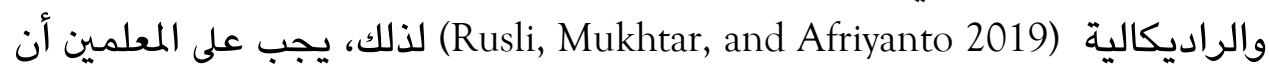
يلعبوا دورا نشطا كوسيلة تعلم الطلبة للتفكير وتطوير الذكاء المعرفي والذكاء العاطفي والذكاء الروحي، حتى يتمكن الطلبة من التعرف على مشاكل الحياة في

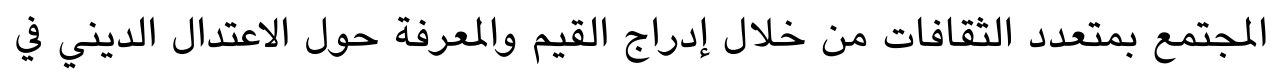
عملية تعليم التربية الإسلامية. ويرى داويخ أن الاعتدال الديني في منظور الإسلام

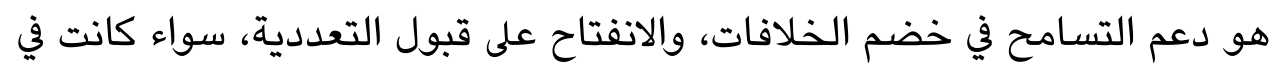


المذهب أو الدين. ولا تعيق الاختلافات التعاون على أساس الإنسانية ( Dawing

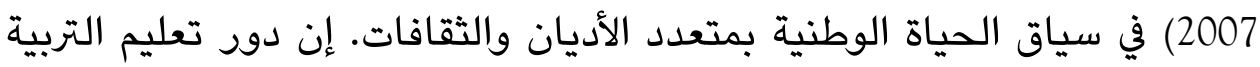
الإسلامية الوسطية يعني تعليم الوسطية أو الإسلام رحمة للعلمين ولا يعلم

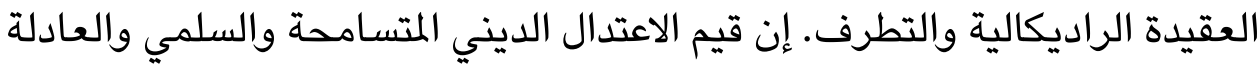
مهمة جدا للطلبة باعتبارها ميزانية القدرة الاجتماعية في التفاعل بين الناس في في

البيئة المدرسية والحياة الاجتماعية (Yunus and Salim 2018; Shallabi 2020). يمكن تطوير الاعتدال الديني من خلال تعليم التربية الإسلامية كأداة مهمة

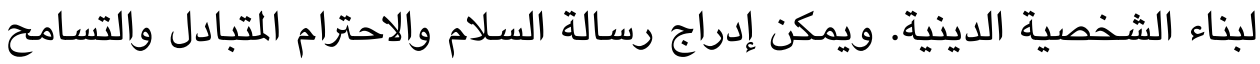
والحاجة إلى العيش في السلام في مضمون المادة التعليمية. بدءا من مرحلة الطفولة إداء

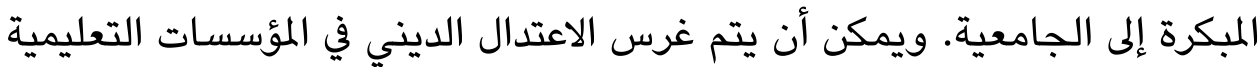

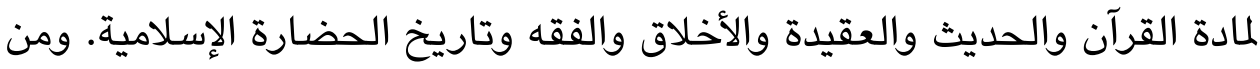

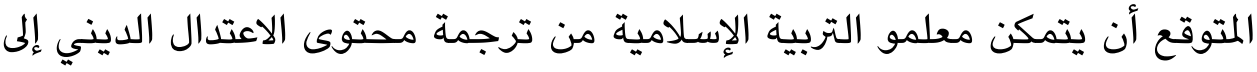
مواد تعليمية لمادة التربية الإسلامية بشكل فعال (AR 2020).

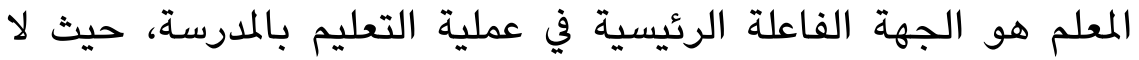

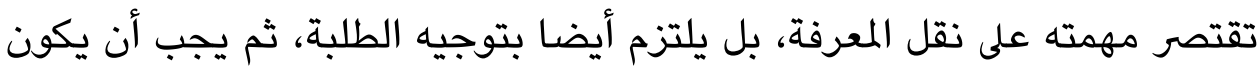

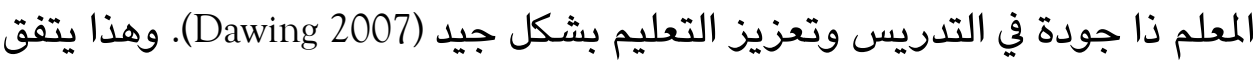

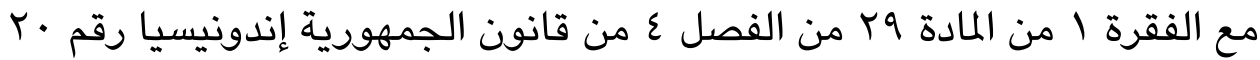

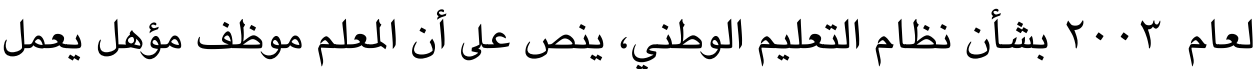

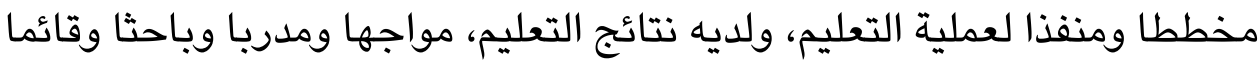
لخدمة المجتمع، وخاصة المحاضر في الجامعات (.Republik Indonesia n.d).

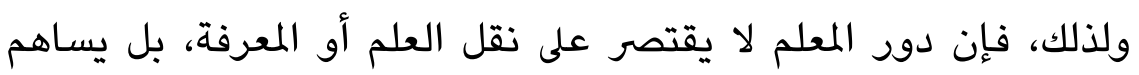

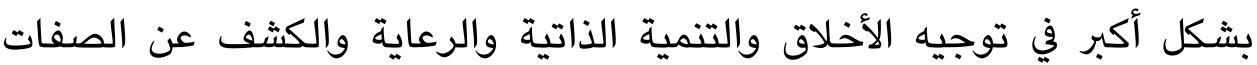

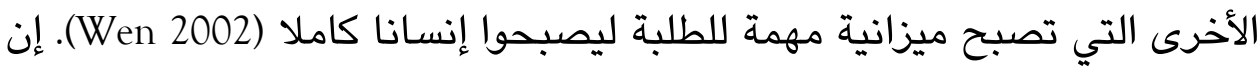
غرس الشخصية الإسلامية الوسطية للطلبة يشكل تحديا كبيرا لمعلم التربية

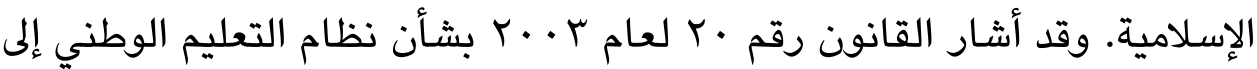


الحاجة الملحة إلى تعليم الشخصيات التي تشكل جزءا من الأهداف التعليمية الوطنية (Ainiyah and Wibawa 2013):

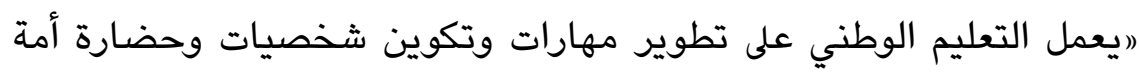

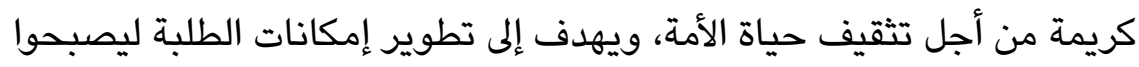

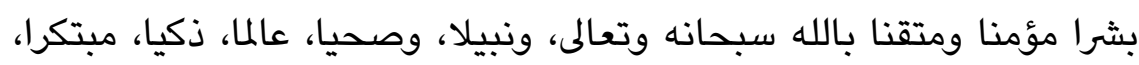
ومستقلا، ومواطنا ديمقراطيا ومسؤوليا،.

لذلك، يجب على المعلم أن يلعب دورا نشطا كوسيلة التعلم للطلبة في

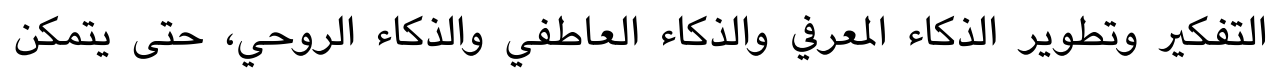

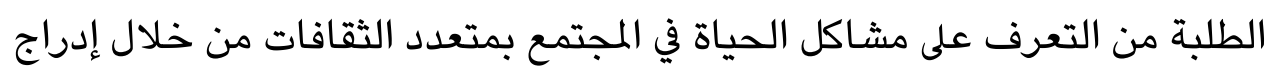
القيم والمعرفة حول الاعتدال الديني في عملية تعليم التربية الإسلامية.

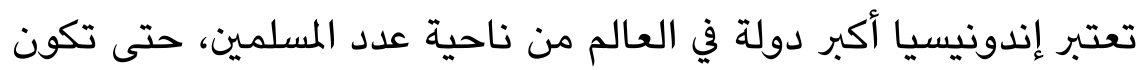

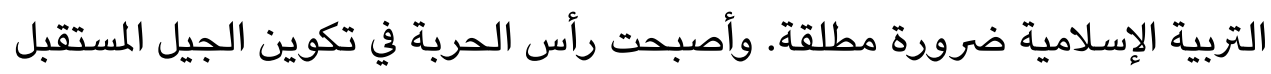

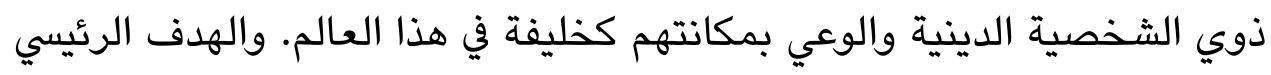
من التربية الإسلامية هو تكوين جيل مؤمن ومتقن بالله سبحانه وتعالى. وإنان التاني

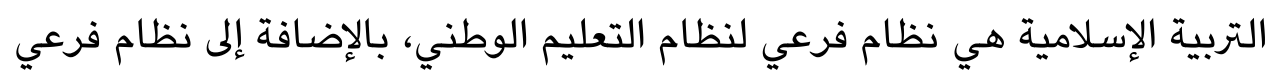

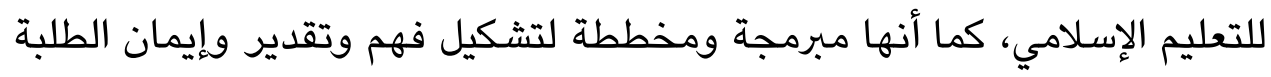

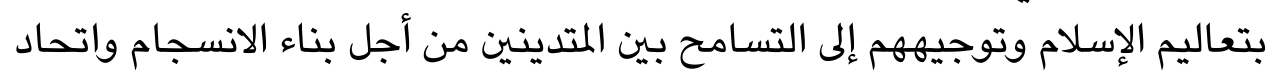

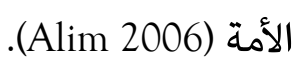

وتحتاج عملية غرس قيم الاعتدال الديني في تعليم التربية الإسلامية إلى

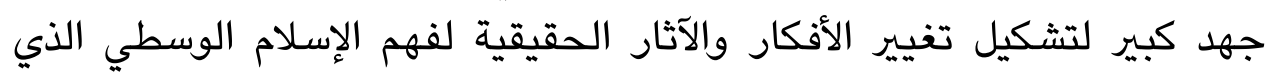

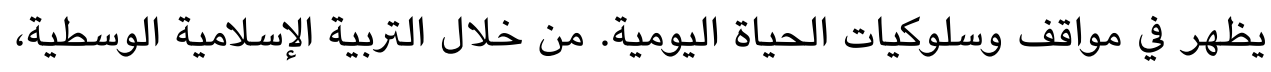

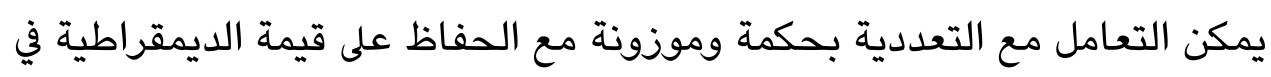

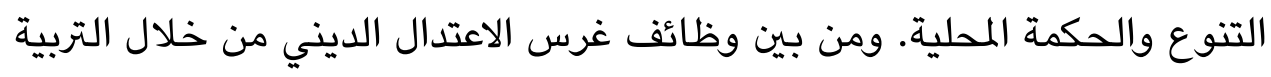

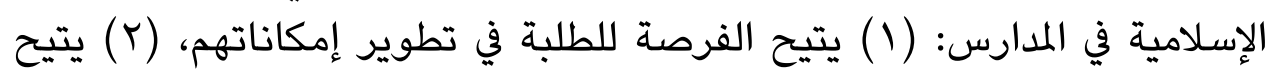

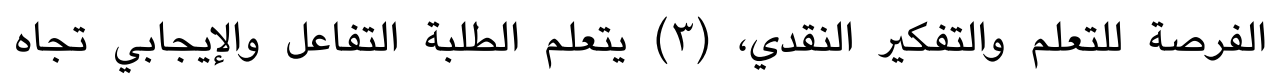

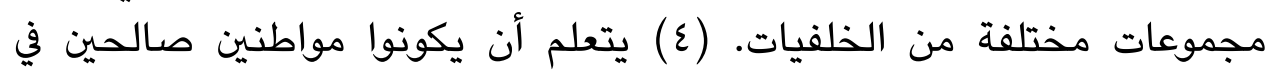


المدرسة وفي المجتمع، (0) يتعلم كيفية تقييم المعرفة من وجهات النظر المختلفة.

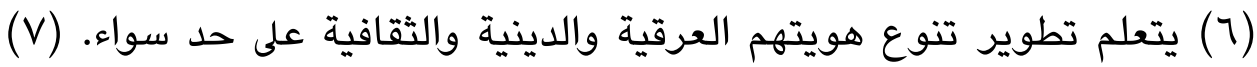

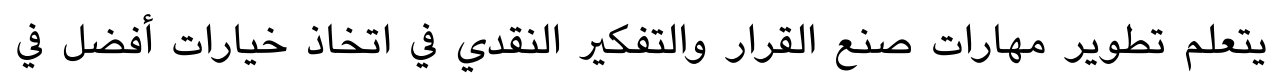
الحياة اليومية.

تتضمن الشخصية الإسلامية الوسطية لدى الطلبة بعدا أيديولوجيا دينيا

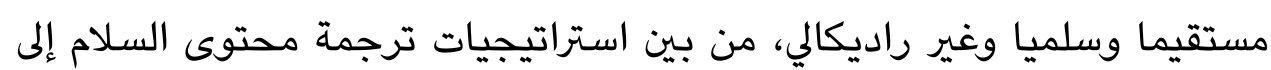

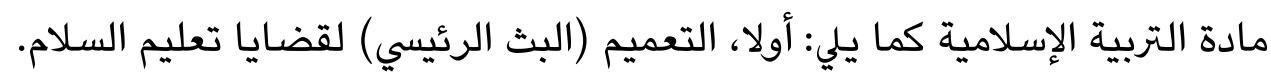

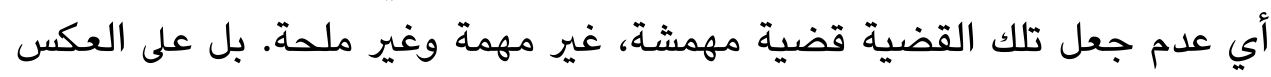
من ذلك، ينبغي أن تكون قضية تعليم السلام هي القضية الرئيسية في غرس القيم

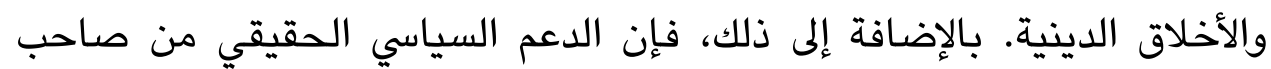

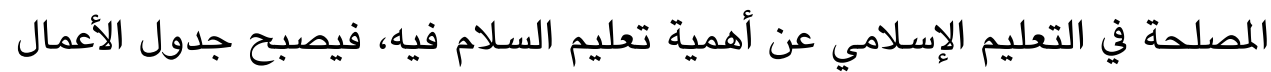

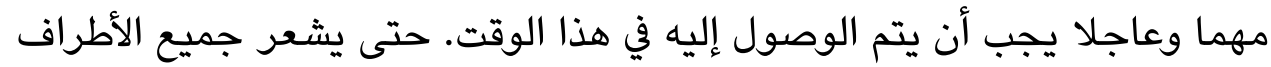

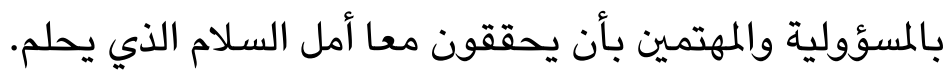

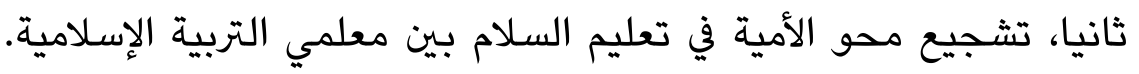

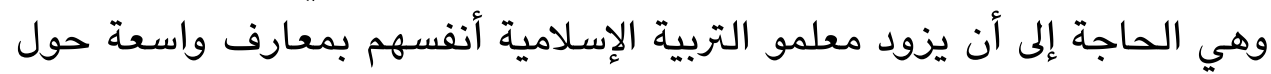

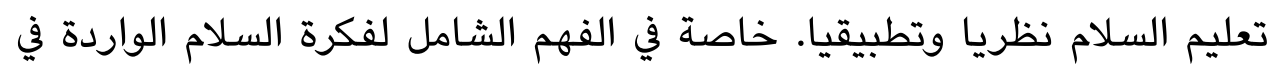

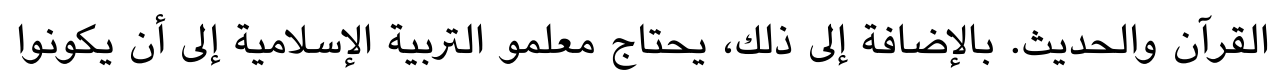
قدوة لموقف متسامح كما يتضح من الرسول والخلفاء الراشدين وخلفاء الإسلام بعده. ثالثا، تعريف الطلاب بقضايا الخطاب والتثقيف في مجال السلام. حيث

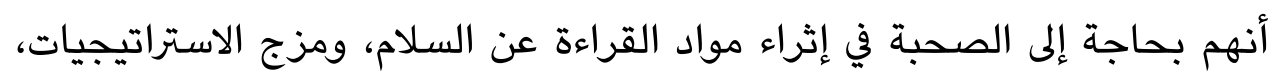

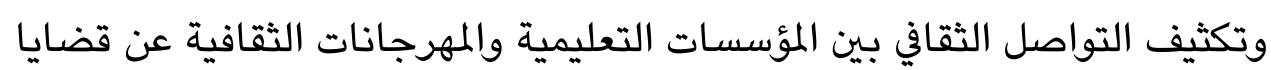
السلام. بحيث يمكن بناء حساسية الطلبة وإدراكهم حول المعنى الحقيقي للأخوة

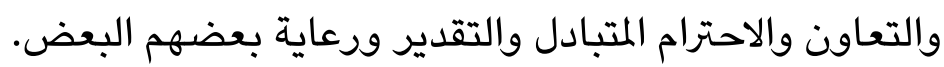

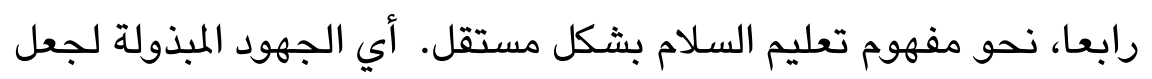
تعليم السلام موضوعا منفصلا، ولم يعد مجرد مادة إضافية مدرجة في في المواد الدينية. أو على الأقل، يساوي مع موقف تعليم الشخصية في المناهج الدراسية 
الحالية (K13). ومع ذلك، ينبغي تعليم المواد التعليمية السلمية بمزيد من المرونة،

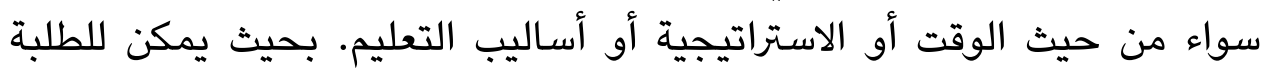

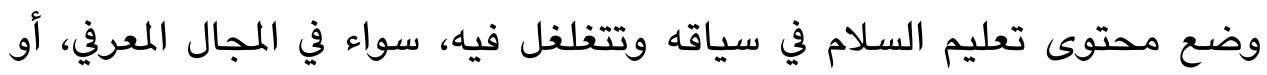

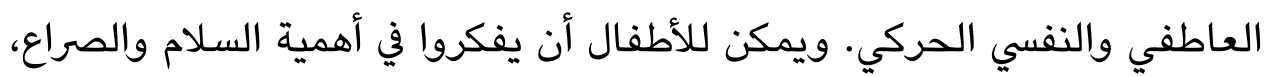

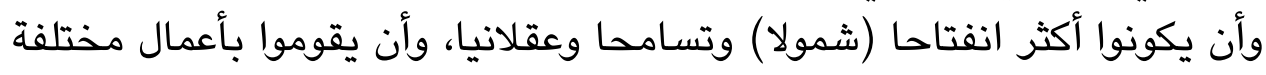

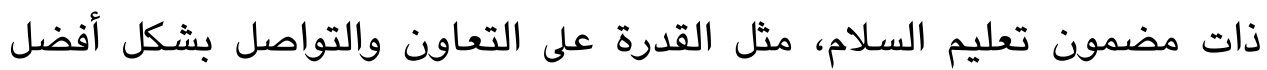
والقدرة على حل المشاكل (Hendry 2015).

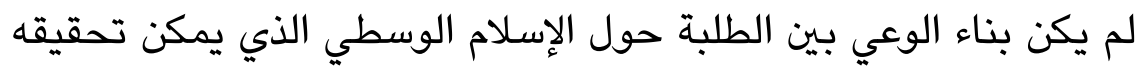

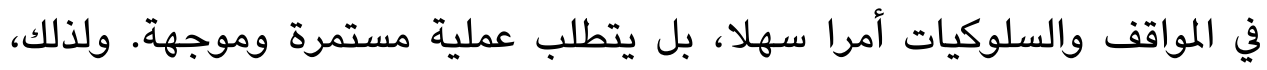

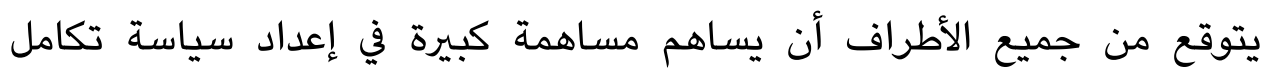

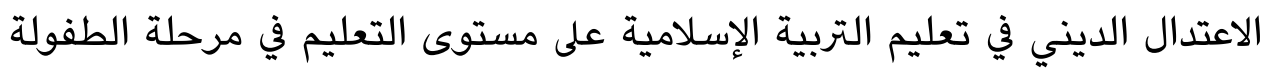

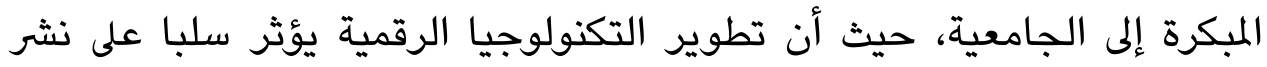

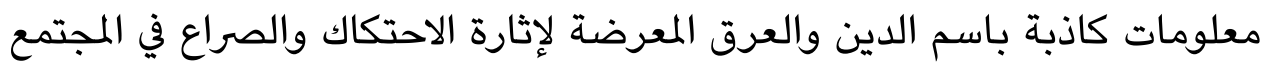
بمتعدد الثقافات (Erzad and Suciati 2018).

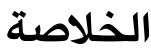

يتم غرس الاعتدال الديني في تعليم التربية الإسلامية بالمدرسة الثانوية

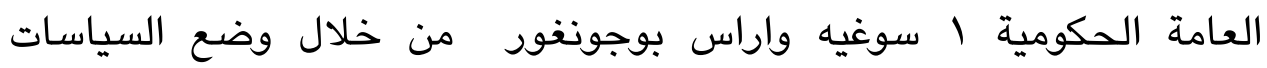

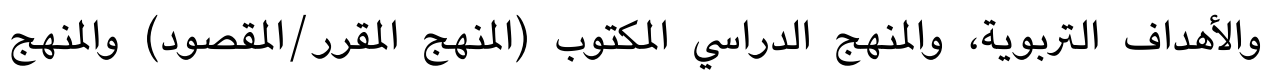

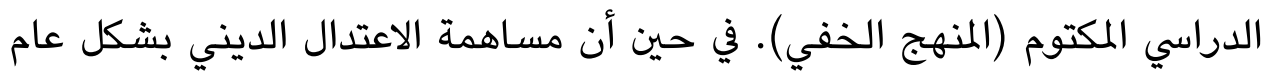

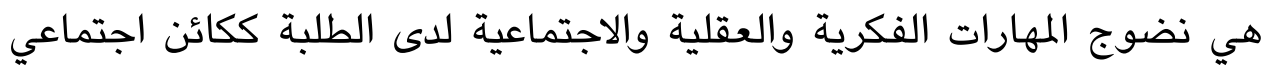

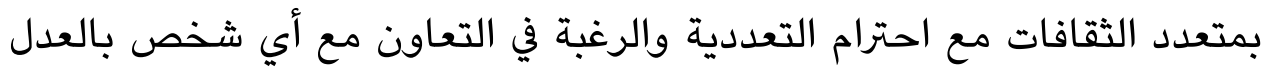
وتحقيق المواءمة والتسامح والانسجام في البيئة المدرسية.

\section{References}

AR, Samsul. 2020. "Peran Guru Agama Dalam Menanamkan Moderasi Beragama." Al-Irfan: Journal of Arabic Literature $\mathcal{E}$ Islamic Studies 3(1): $37-51$. 
DOI: https://doi.org/10.36835/al-irfan.v3i1.3715.

Afrizal, Nur and Mukhlis Lubis. 2015. "Konsep Wasathiyah Dalam AlQur'an: Studi Komparatif Antara Tafsir at-Tahrir Wa at-Tanwir Dan Aisar at-Tafsir." Jurnal An-Nur 4(2): 205-25.

Akhmadi, Agus. 2019. "Moderasi Beragama dalam Keragaman Indonesia." Jurnal Diklat Keagamaan 13(2): 45-55.

Ainiyah, Nur and Nazar Husain Hadi Pranata Wibawa. 2013. "Pembentukan Karakter Melalui Pendidikan Agama Islam." Jurnal alUlum 13(1): 25-38.

Alim, Muhammad. 2006. Pendidikan Agama Islam: Upaya Pembentukan Pemikiran Dan Kepribadian Muslim. Bandung: Rosdakarya.

Ali, Muhammad. 2003. Teologi Pluralis-Multikultural: Menghargai Kemajemukan, Menjalin Kebersamaan. Jakarta: Penerbit Buku Kompas.

Ali, Muhammad. 2002. Guru dalam Proses Belajar Mengajar. Bandung: Algensindo.

Azra, Azyumardi. 2007. Merawat Kemajemukan Merawat Indonesia, Seri Orasi Budaya. Yogyakarta: Penerbit Impulse.

Baidhawy, Zakiyuddin. 2005. Pendidikan Agama Berwawasan Multikultural. Jakarta: Earlangga.

Clark, Janine A. 2006. "The Conditions of Islamist Moderation: Unpacking Cross-Ideological Cooperation in Jordan." International Journal of Middle East Studies 38(4): 539-60. Retrieved July 13, 2021, from http://www.jstor.org/stable/4129147.

Dawing, Darlis. 2017. "Mengusung Moderasi Islam di Tengah Masyarakat Multikultural." Rausyan Fikr: Jurnal Ilmu Ushuluddin dan Filsafat 13(2): 225-55.

DOI: https://doi.org/10.24239/rsy.v13i2.266.

Driyarkara, Driyarkara. 1980. Tentang Pendidikan. Jakarta: Kanisius.

Erzad, Azizah Maulina and Suciati Suciati. 2018. "The Exsistence of Kudus Islamic Local Culture to Prevent Radicalism in Globalization Era." QIJIS: Qudus International Journal of Islamic Studies 6(1): 39-56.

DOI: http://dx.doi.org/10.21043/qijis.v1i1.3460. 
Faozan, Ahmad. 2020. "Moderasi Beragama Dalam Pendidikan Agama Islam Untuk Masyarakat Multiklultur." Hikmah: Journal of Islamic Studies 16(2): 220-28.

DOI: http://dx.doi.org/10.47466/hikmah.v16i2.170.

Hendry, Eka. 2015. "Pengarus Utamaan Pendidikan Damai (Peaceful Education) Dalam Pendidikan Agama Islam (Solusi Alternatif Upaya Deradikalisasi Pandangan Agama)." At-Turats: Jurnal Pemikiran Pendidikan Islam 9(1): 4-13.

DOI: https://doi.org/10.24260/at-turats.v9i1.303.g257.

Hermawan, Ajib. 2020. "Nilai Moderasi Islam dan Internalisasinya di Sekolah.” INSANIA: Jurnal Pemikiran Alternatif Kependidikan 25(1): 3143.

DOI: https://doi.org/10.24090/insania.v25i1.3365.

Islam, Tazul, and Amina Khatun. 2015. "Islamic Moderation in Perspectives: A Comparison Between Oriental and Occidental Scholarship." International Journal of Nusantara Islam 3(2): 69-78.

DOI: https://doi.org/10.15575/ijni.v3i2.1414.

Miles, Mathew B. and A. Michael Huberman. 2009. Analisis Data Kualitatif: Buku Sumber Tentang Metode-Metode Baru. Trans. Tjetjep Rohendi Rohidi. Jakarta: Universitas Indonesia Press.

Muhtarom, Muhtarom. 2018. "Urgensi Penguatan Pemikiran Moderasi Islam dalam Pendidikan Agama di Madrasah." Tatar Pasundan: Jurnal Diklat Keagamaan 12(32): 39-47.

DOI: https://doi.org/10.38075/tp.v12i32.53.

Mujtahid, Mujtahid. 2017. "Model Implementasi Pendidikan Karakter Melalui Pendekatan Terintegrasi Dalam Perkuliahan Pada Jurusan PAI - FITK UIN Maulana Malik Ibrahim Malang.” Ulul Albab: Jurnal Studi Islam 17(2): 230-52.

DOI: https://doi.org/10.18860/ua.v17i2.3832.

Nashuddin, Nashuddin. 2020. "Aktualisasi Nilai-Nilai Pendidikan Islam Dalam Merevitalisasi Pemahaman Moderasi Pada Lembaga Pendidikan Di Indonesia." Schemata 9(1): 33-52.

DOI: https://doi.org/10.20414/schemata.v9i1.2159. 
Nata, Abuddin. 2016. Islam Rahmatan Lil Alamin sebagai Model Pendidikan Islam Memasuki ASEAN Community. UINJKT, http://abuddin.lec.uinjkt.ac.id/articles/islam-rahmatan-lil-alaminsebagai-model-pendidikan-islam-memasuki-asean-community

Rahman, Khalid, and Aditia Muhammad Noor. 2020. Moderasi Beragama di Tengah Pergumulan Ideologi Ekstremisme. Malang: Universitas Brawijaya Press.

Republik Indonesia. n.d.. Undang-undang Republik Indonesia Nomor 20 Tahun 2003 tentang Sistem Pendidikan Nasional

Rozi, Syaikhu. 2019. "Pendidikan Moderasi Islam KH. Asep Saifuddin Chalim; Mencegah Radikalisme Agama dan Mewujudkan Masyarakat Madani Indonesia." Tarbiya Islamia: Jurnal Pendidikan dan Keislaman 8(1): 26-43.

DOI: https://doi.org/10.36815/tarbiya.v8i1.343.

Rusli, Ris'an, Aflatun Muchtar, and Afriyanto Afriyanto. 2019. "Islamic Moderation in Higher Education." International Journal of Opcion 35(89): 2899-921.

https://produccioncientificaluz.org/index.php/opcion/article/view/2 9802.

Shallabi, Ali Muhammad. 2020. Wasathiyah Dalam Al-Qur'an: Nilai-nilai Moderasi Islam dalam Akidah, Syariat, dan Akhlak. Trans. Samson Rahman and Tajuddin. Jakarta: Pustaka Al-Kautsar.

Sondang, Aprida. 2018. Membangun Budaya Damai dari Sekolah. Wahid Foundation.http://wahidfoundation.org/index.php/news/detail/Me mbangun-Budaya-Damai-Mulai-dari-Sekolah.

Purwanto, Yedi, Qowaid Qowaid, Lisa'diyah Ma'rifataini, and Fauzi Ridwan. 2019. "Internalisasi Nilai Moderasi Melalui Pendidikan Agama Islam (PAI) di Perguruan Tinggi Umum.” Edukasi: Jurnal Penelitian Pendidikan Agama dan Keagamaan 17(2): 110-24.

DOI: http://dx.doi.org/10.32729/edukasi.v17i2.605.

Wen, Sayling. 2002. Future of Education: Masa Depan Pendidikan. Trans. Arvin Saputra. Batam: Lucky Publisher.

Yunus, Yunus and Arhanuddin Salim. 2018. "Eksistensi Moderasi Islam 
dalam Kurikulum Pembelajaran PAI di SMA." Al-Tadzkiyyah: Jurnal Pendidikan Islam, 9(2): 181-94.

DOI: https://doi.org/10.24042/atjpi.v9i2.3622. 